WFPS-TME-092

JULY 1978

\title{
ANALYSIS OF TOROIDAL VACUUM VESSELS \\ FOR USE IN DEMONSTRATION SIZED TOKAMAK REACTORS
}

\author{
MICHAEL E, CULBERT \\ UNIVERSITY OF PITTSBURGH
}

COOPERATIVE GRADUATE EDUCATION PROGRAM IN FUSION TECHNOLOGY ADMINISTERED FOR THE U.S. DEPARTMENT OF ENERGY

BY THE WESTINGHOUSE ELECTRIC CORPORATION

CONTRACT EG-77-C-02-4231-A000 


\section{DISCLAIMER}

This report was prepared as an account of work sponsored by an agency of the United States Government. Neither the United States Government nor any agency Thereof, nor any of their employees, makes any warranty, express or implied, or assumes any legal liability or responsibility for the accuracy, completeness, or usefulness of any information, apparatus, product, or process disclosed, or represents that its use would not infringe privately owned rights. Reference herein to any specific commercial product, process, or service by trade name, trademark, manufacturer, or otherwise does not necessarily constitute or imply its endorsement, recommendation, or favoring by the United States Government or any agency thereof. The views and opinions of authors expressed herein do not necessarily state or reflect those of the United States Government or any agency thereof. 


\section{DISCLAIMER}

Portions of this document may be illegible in electronic image products. Images are produced from the best available original document. 
WFPS-TME-092

JULY 1978

\section{ANALYSIS OF TOROIDAL VACUUM VESSELS FOR USE}

IN DEMONSTRATION SIZED TOKAMAK REACTOR

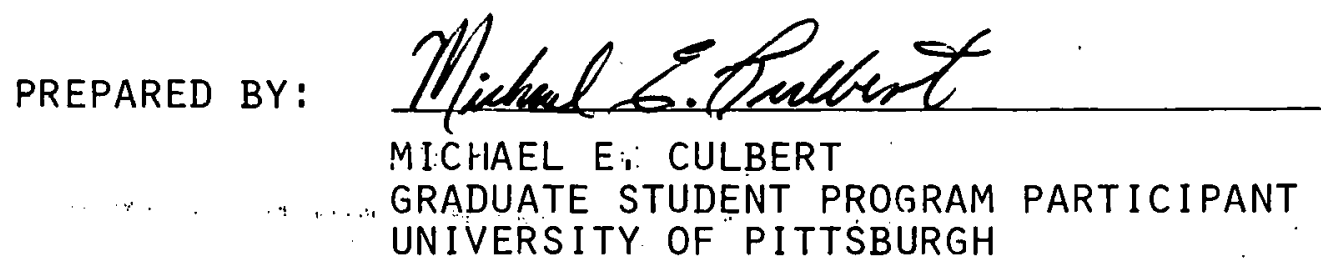

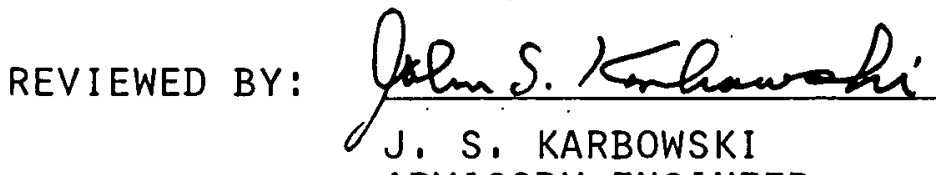
ADV I SORY ENG INEER

MECHAN I CAL ENG I NEER I NG

APPROVED BY:


ENG I NEER I NG






\section{ACKNOWLEDGMENT}

This work was performed for the U. S. Department of Energy, under Contract EG-77-C-02-4231-A000, Cooperative Graduate Education Program in Fusion Technology. Reproduction, translation, publication, use and disposal in whole or in part, by or for the United States Government is permitted.

The author wishes to express his deep appreciation to his project advisors, Dr. T. C. Woo, Dr. Alan Y. Lee, J. S. Karbowski and J. W. French for their valuable suggestions and encouragement in formulating this study. Also, to T. C. Varljen for his constructive criticism in the latter stages and to Dr. D. Klein for his effort in program coordination. A special thanks to my fellow graduate students Eric Frantz, John Easoz, Todd Pridgeon and John McCowan.

\section{LEGAL NOTICE}

This report was prepared as an account of Government sponsored work. Neither the United States, nor the Administration, nor any person acting on behalf of the Administration:

A. Makes any warranty or representation, expressed or implied, with respect to the accuracy, completeness, or usefulness of the information cuntained in this report, or that the use of any information, apparatus, method or process disclosed in this report may not infringe privately owned rights; or

B. Assumes any liabilities with respect to the use of, or for damages resulting from the use of any information, apparatus, method, or process disclosed in this report. 


\section{ABSTRACT}

The vacuum vesse 1 component of the tokamak fusion reactor is the subject of this study. The main objective of this paper was to provide guidance for the structural design of a thin wall externally pressurized toroidal vacuum vessel. The analyses are based on the available state-of-the-art analy.tical methods. The shortcomings of these analytical methods necessitated approximations and assumptions to be made throughout the study.

A principal result of the study has been the identification of a viable vacuum vessel design for the Demonstration Tokamak Hybrid Reactor (DTHR) and The Next Step (TNS) Reactor. 
TABLE OF CONTENTS

1.0 Introduction

Page

$1-1$

2.0 Vacuum Vessel Stability Analysis 2-1

2.1 Stability Analysis for the D Meridian Torus 2-3

2.2 Stability Analysis for a Cylindrical Shell 2-9

2.2.1, Discussion 2 . 2-12

2.3 Stability Analysis for Cylindrical Shells, of Various 2-12 Structural Elements.

$\begin{array}{ll}2.3 .1 & \text { Sandwich Cylindrical Shell 2-14 }\end{array}$

2.3.2. Rib-Stiffened Cylindrical Shell 2-19

2.3.3. Integrally Stiffened Cylindrical Shell 2-21

2.4 Conctusions 2-26

3.0 Stress Analysis of the Vacuum Vessel 3-1

3.1 Stress Analysis of the Monocoque Shell 3-1

3.2 Stress Analysis of the Rib-Stiffened Shell 3-4

4.0 Conceptual Design of the Two Component Vacuum Vesse1 She11 4-1

4.1 Thermat and Hydraulic Design $4-3$

4.2 Stress Analysis of the Tubular Wall 4-5

4.3 Stiffener-Coolant Manifold Rib Design Concept 4-14

4.4 Summary of the Two Component Vacuum Vessel Design and 4-17 Corrclusions

5.0 ?eferences $5-1$ 


\section{LIST OF FIGURES}

FIGURE

Page

$2-1$ TNS Plasma Containment Vessel Dimensions 2-2

2-2 Buckling Curves for Toroidal Shells 2-6

2-3 Possible Buckling Modes for a Toroidal Shell with a 2-7. Circular Cross Section

2-4 Preliminary Buckling Mode Geometry for the D Meridian 2-8 Toroidal Shell

2-5 Buckling Curves for Straight Cylindrical Shells Having . 2-10 a Buckling Mode of $n=2$

2-6 Buckling Curves for Elliptic and Circular Cylindrical 2-13 Shells

2-7 Sandwich Shell Section. 2-15

2-8 Sandwich Shell's Radial Cross-Sectional Area Versus 2-18 Critical Buckling Pressures

2-9. Rib-Stiffened Sheli $\quad 2-20$

2-10 Various Stiffening Forms 2-22

2-11 Stiffener Spacing Versus. Panel Thickness for Various . . . . 2-23 External Pressures

2-12. Needed Area Moment of Inertia of the Stiffener for 2-24 Various Panel Lengths and External Pressures

2-13 Integrally Stiffened Shell 2-25

2-14 Radial Cross-Section Area Versus Critical Buckling $\quad 2-27$ Pressures for Various Shell Structural Elements

3-1 The Meridian and Toroidal Stresses for the Elliptic 3-3 Toroid Under Uniform External. Pressures.

3-2 Hoop Stress Versus Wall Thickness for Stresses Induced 3-5 From Continuous Support of a Monocoque Shell 


\section{LIST OF FIGURES (Continued)}

FIGURE

Page

3-3 Potential Stiffener-Coolant Manifold Rib Design 3-8

4-1 DTHR Vacuum Vessel Concept $4-4$

4-2 Two Dimensional Finite Element Model of the Thermal- 4-8 Structural Wall Cross Section

4-3 Tubular First Wall

$4-10$

4-4 Design Fatigue Curve for Austenitic Steels, NickelChromium-Iron Alloy, Nickel-Iron Chromium Alloy, and Nickel-Copper Alloy

4-5 Stiffener-Coolant Manifold Rib Concept

4-6 Stiffener Rib Concept 


\section{LIST OF TABLES}

\section{TABLE}

Page

1-1 First Wall Parameters for the TNS Toroidal Vacuum Vessel

2-1. Optimum Dimensions for a Sandwich Vacuum Vesse1

4-1 Conceptual Design Parameters of the Vacuum Vessel

4-2 Summary of the Vessel's First Wall Cooling Parameters 


\subsection{INTRODUCTION}

This study was conducted to provide guidance for the structural design of toroidal vacuum vessel structures for tokamak fusion devices. In order to start with a consistent set of boundary conditions, an early version of the TNS (The Next Step) tokamak conceptual design (1) was used as the basis for the study. The TNS design was developed by an ORNL/Westinghouse team and was directed at the definition of a near-term, moderately long pulse, ignition test reactor.

The principal function of the vacuum vessel structure is to provide a vacuum containment within which a plasma can be generated and controlled. The vessel must be designed to suitably bound the plasma during all modes of operation and to provide structural integrity for the severe thermal and mechanical stresses induced upon the structure. The vessel structure must be cooled below or near $500^{\circ} \mathrm{C}$ with minimal pumping power. The $500^{\circ} \mathrm{C}$ metal temperature is the threshold above which the mechanical properties of the referenced vessel material deteriorates rapidly.

Some of the principal design parameters for the present study are 1 isted as follows:

- The vessel meridian is defined to have a geometry representing a 0 . Also, the vessel's minor and major axes along with the elongation coefficient. were defined.

- The vacuum vessel material is specified as 316 stainless steel.

- The vessel coolant is referenced as pressurized water.

- The study assumes a continuous shell without penetrations.

- The vessel is subjected to a uniform external pressure of one atmosphere during operation.

- A nuclear heating rate of $45 \mathrm{w} / \mathrm{cm}^{3}$ and a surface flux of $2.65 \mathrm{MW} / \mathrm{m}^{2}$ are the thermal loads imposed upon the vessel. 
- The duty cycle is 300 seconds which includes a full power burn pulse of 30 seconds.

- The vessel cyclic 1 ifetime is specified as $1 \times 10^{6}$ temperature cycles (approximately 10 years of usage).

The principal structural load on the vessel is a uniform one atmosphere external pressure when the torus is evacuated to $10^{-8}$ torr inside. The principal stresses due to this load are compressive. Failure in the vessel structure may occur in either of two ways, depending upon the design. A relatively thick wall vessel would fail by the stresses in the vessel walls reaching the yield point, while a relatively thin wall vessel would fail by instability or buckling of walls at stresses which may be considerably below the yield point of the vessel material. Optimum neutronic performance is a vital characteristic of the overall reactor, thus the structural mass of the vessel must be kept to a minimum. The design objective of this study is to design a thin wall vessel, where the structural stability of the shell must be considered.

The initial thrust of the study was directed towards determining viable methods for calculating the buckling strength of potential structural elements. This analysis identified a viable vacuum vessel structural cross section that was mass efficient in respect to the other cross sections considered. From the basis of this conclusion, the final objective of the study, a conceptual design for the DTHR (Demonstration Tokamak Hybrid Reactor) vacuum vessel was met. The vacuum vessel design requirements, for the DTHR are very similar to those of the TNS, thus the design parameters are consistent.

The DTHR is currently being proposed as one of the next potential experimental fusion devices. The conceptual design of the DTHR is presently being done by the Fusion Power Systems Department (Westinghouse team) under funding provided by the Department of Energy. The main objective of the Westinghouse DTHR study is a preliminary conceptual design for a near-term hybrid reactor. Such an approach necessitates the use of available coolants and structural materials in the operating components of the hybrid reactor. As a consequence, the conceptual design is limited to less than an optimum performance.

Table 1-l lists values of frequently used parameters throughout the study. 
TABLE $1-1$

FIRST WALL PARAMETERS FOR THE TNS TOROIDAL VACUUM VESSEL

Material

E, Young's Modulus $\left(T=500^{\circ} \mathrm{C} \mathrm{MPa}\right)$

$v$, Poisonn's Ratio

$\sigma_{y}$, Average Yield Stress $\left(T=500^{\circ} \mathrm{C}\right) \mathrm{MPA}$

$\gamma$, Weight Density, $\mathrm{kgs} / \mathrm{m}^{3}$

R, Major Radius of Toroidal Shell, $m$

a, Midplane Minor Radius of Toroidal Shell, m q"', Neutron Gamma Heating, $W / \mathrm{cm}^{3}$

$q^{\prime \prime}$, Surface Heating, $M W / \mathrm{m}^{2}$

P, External Pressure, MPa
316 S.S.

155,800

0.3

120.7

7,861

5

1.65

45

2.665

0.1014 


\subsection{VACUUM VESSEL STABILITY ANALYSIS}

The failure of the vessel is assumed to be the critical elastic buckling load of the vessel although it should be recognized that there may be some reserve strength after buckling. To determine the magnitude of this reserve strength, post-buckling analysis would be required. Since the buckled configuration would be objectionable, it is felt that post-buckling analysis would be unnecessary. Other significant parameters are also neglected. These include. stress concentrations due to penetrations and connections and, also, the decrease in stiffness of the material as the yield point of the material is approached.

Illustrated in Figure 2-1 are the dimensions for the plasma containment vessel. These dimensions for the vessel fall beyond the scope of any previous analytical work in the structural stability area. An attempt is made to calculate the initial buckling pressure for the $D$ meridian torus for various cross-sectional structural elements. The calculations are based upon logical application of accepted theories that are capable of establishing reasonable extrapolations which result in an approximation of the critical buckling pressures of the structure.

Approximations of the critical buckling pressures are determined by using analytical results for torus, shallow shell segments of toroidal shells and various cross-sectional cylinders. More accurate predictions for the critical buckling pressures can be obtained using existing thin shell computer codes $(2,3,4)$. However, using numerical methods as the analysis technique to establish the vacuum vessel dimensions is time-consuming and high in computer cost. Such modeling should be implemented only after a reasonable first approximate design has been established. Even though this analytical solution would be approximate, it would still provide valuable physical insight and guidance for more refined numerical modeling. 


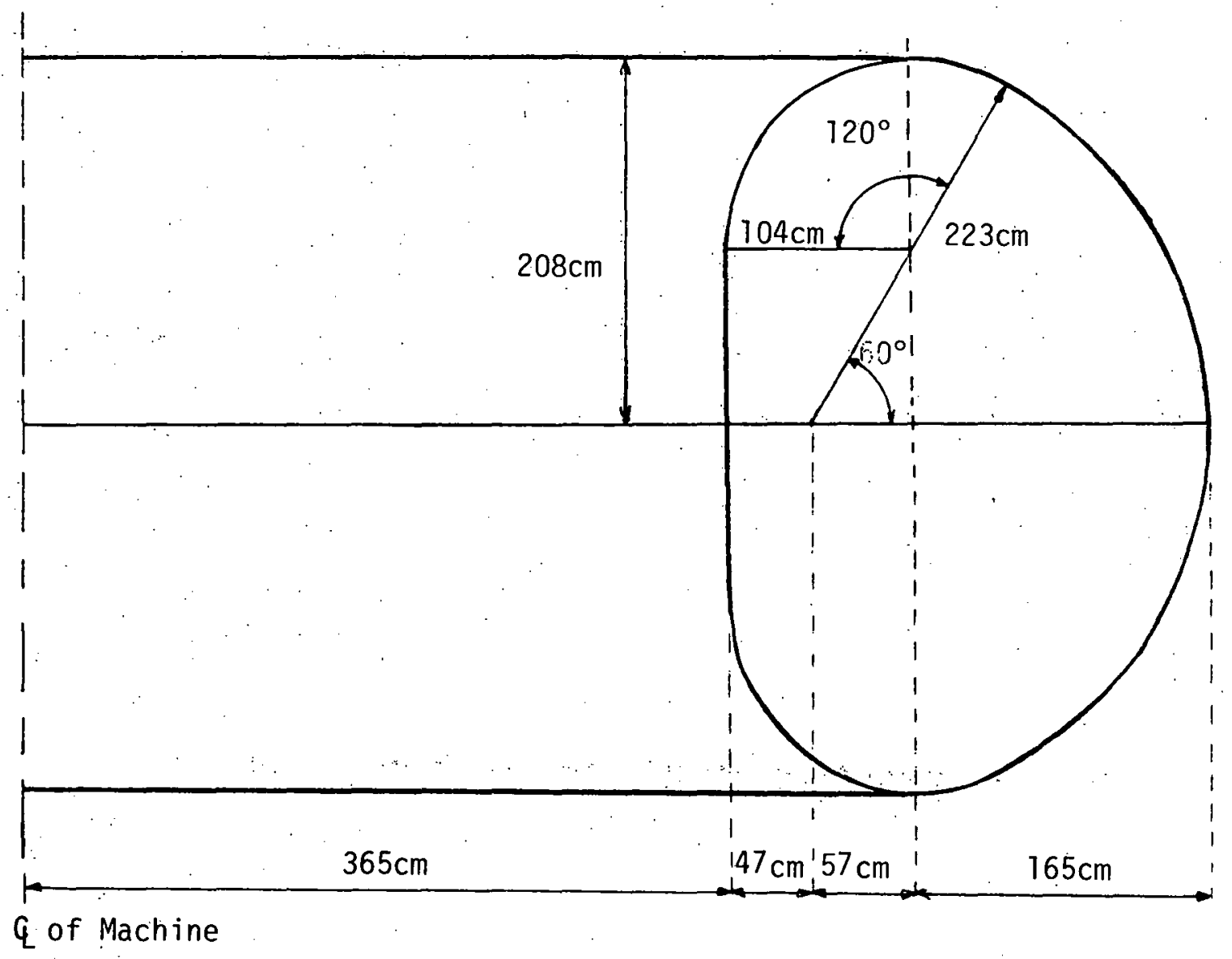

Figure 2-1. TNS Plasma Containment Vessel Dimensions 


\subsection{STABILITY ANALYSIS FOR THE D MERIDIAN TORUS}

There have been no papers published dealing with analysis of the stability of a $D$ meridian toroidal shell geometry. Even with respect to a circular meridian torus, there is very limited work on the stability analysis. In both cases, the theoretical analysis is hampered by algebraic complications. Also, the literature discloses no general agreement among the investigators in the field as to a valid choice of simplifying approximations for the governing equations nor to the best means to represent the buckled geometry. Thus, one must resort to various approximate methods to analyze the stability of the D meridian torus.

The stability of a circular toroidal shell loaded from uniform external pressure was treated in a general closed form method by Sobel and Flügge ${ }^{(5)}$. Their results were represented in buckling curves which can be adapted to the TNS geometric parameters. Linear membrane analysis was used in their work for deriving the prebuckling solution. The stability equations for a toroidal shell are obtained through specialization of the equations governing the stability of a general shell of revolution. The stability equations were solved by the use of series expansions in the circumferential and meridianal directions for the displacement components that develop during buckling. It was initially determined that a toroidal shell under hydrostatic pressure can buckle into a mode that is either symmctric or asymmetric. They investigated both of these modes separately for a wide range of parametric parameters.

The stability analysis for the D meridian will be directed towards the elliptical section, since there is no analytical technique for handling the $D$ cross-section. The elliptical portion represents approximately $80 \%$ of the $D$ meridian peripheral length. It is recognized that the bending stresses at these discontinuities of curvature will require local strengthening. The increase in shell strength in the straight section of the $D$ should be such that yielding occurs simultaneously at every point in the $D$ meridian. 
In determining a justifiable radius for representing the $D$ meridian, one has various options at hand. One obvious approximation would be to use the radius of curvature of the elliptic portion of the $D$ meridian at the extremity of its minor axis, which is 223 centimeters, as the radius for a circular meridian torus. Another approximation would be to implement Roman and Kempner's ${ }^{(6)}$ findings. They determined that the stress and displacement values for an oval cylinder (major to minor axis ratio 1.1) can be very closely approximated by a circular cylinder that has a circumerence equal to that of the oval's periphery. Thus, the radius of curvature of the circular meridian is $r=\frac{L_{e}}{2 \pi}$, which is 184 centimeters.

Where, $L_{e}=$ Peripheral length of oval

$r=$ Radius of approximated circular meridian

For a meridian radius of 223 centimeters, with the toroid having an axis of revolution of 411 centimeters, Sobel and Flügge ${ }^{(5)}$ found the critical buckling pressures, Pcr, for various shell thicknesses, $h$, to be as follows:

$$
\begin{aligned}
& \frac{\operatorname{Pcr}\left(r^{2}\right)}{E^{2}}=\left\{\begin{array}{l}
0.0490 ; r / h=25 \\
0.0370 ; r / h=50 \\
0.0280 ; r / h=100 \\
0.0218 ; r / h=200 \\
0.0160 ; r / h=500
\end{array}\right. \\
& \text { With Pcr }=\left\{\begin{array}{l}
13.51 \mathrm{MPa} ; \mathrm{h}=(8.940 \mathrm{~cm}) \\
2.55 \mathrm{MPA} ; \mathrm{h}=(4.470 \mathrm{~cm}) \\
0.48 \mathrm{MPA} ; \mathrm{h}=(2.235 \mathrm{~cm}) \\
0.09 \mathrm{MPA} ; \mathrm{h}=(1.117 \mathrm{~cm}) \\
0.01 \mathrm{MPA} ; \mathrm{h}=(0.447 \mathrm{~cm})
\end{array}\right.
\end{aligned}
$$

For a meridian radius of 184 centimeters with the toroid having an axis of revolution of 470 centimeters, the critical buckling pressures are as follows: 


$$
\begin{aligned}
& \frac{\operatorname{Pcr}\left(r^{2}\right)}{E h^{2}}=\left\{\begin{array}{l}
0.0400 ; r / h=25 \\
0.0300 ; r / h=50 \\
0.0230 ; r / h=100 \\
0.0180 ; r / h=200 \\
0.0128 ; r / h=500
\end{array}\right. \\
& \text { With Pcr }=\left\{\begin{array}{r}
11.032 \mathrm{MPa} ; h=(7.3760 \mathrm{~cm}) \\
2.068 \mathrm{MPa} ; \mathrm{h}=(3.6880 \mathrm{~cm}) \\
0.396 \mathrm{MPA} ; \mathrm{h}=(1.8440 \mathrm{~cm}) \\
77.568 \mathrm{KPA} ; \mathrm{h}=(0.9220 \mathrm{~cm}) \\
8.825 \mathrm{KPA} ; \mathrm{h}=(0.3688 \mathrm{~cm})
\end{array}\right.
\end{aligned}
$$

Figure 2-2 illustrates the critical buckling curves for the two different sized toroidal shells. In examining the curves, one finds that the larger circular meridian torus is represented by a buckling curve that is approximately $8.5 \%$ more conservative than the other shell.

For the circular torus, Sobel and Flügge ${ }^{(5)}$ found that the critical buckling mode has two circumferential waves $(n=2)$ that can be either symmetric or asymmetric about the horizontal midline of the circular cross-section for geometric parameters similar to those of the TNS. These two circumferential lobes are formed as follows: as the external pressure approaches the shells' critical pressure,. the circular cross-section will assume elliptical forms and eventually collapse by instability. The cross-section will flatten out, with two bulges extending outward beyond the original cross-sectional form and two extending inward, forming what is commonly known as a two-lobe collapse. For the shell to buckle in an asymmetric mode with $n=0$ circumferential wave, the estimated pressure is slightly higher than that for the $n=2$ mode. Thus, it is conceivable that the real buckling mode may occur in any of these three possible mode geometries which are illustrated in Figure 2-3.

There was a preliminary investigation by Stancampiano ${ }^{(9)}$ for determining the elastic buckling mode shape for the $D$ meridian toroidal shell. His findings are shown in Figure 2-4; He utilized the finite element technique in resolving the problem. In examining the prebuckle geometry, it appears to have $n=2$ symmetric 


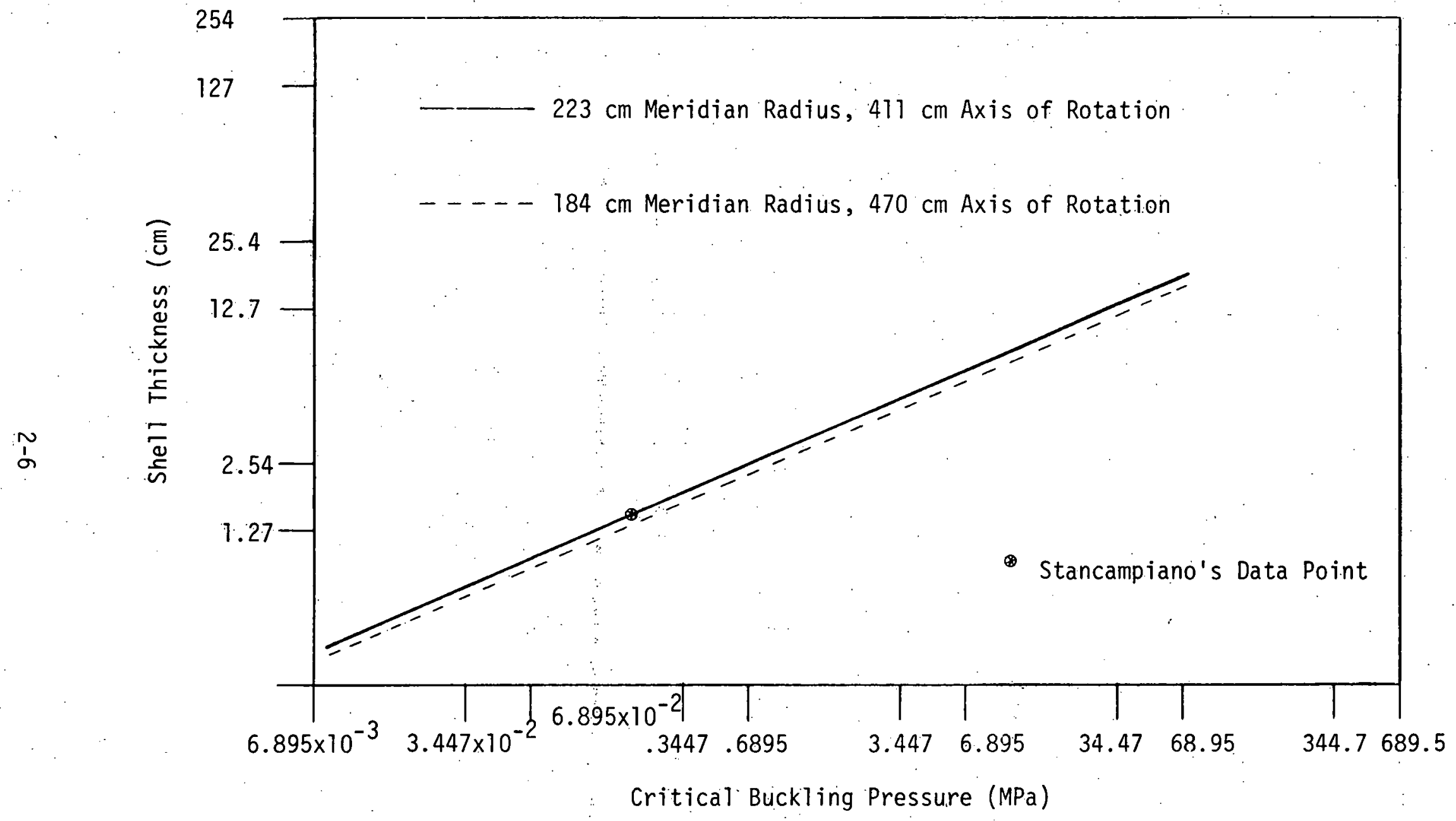

Figure 2-2. Buckling Curves for Toroidal Shells 


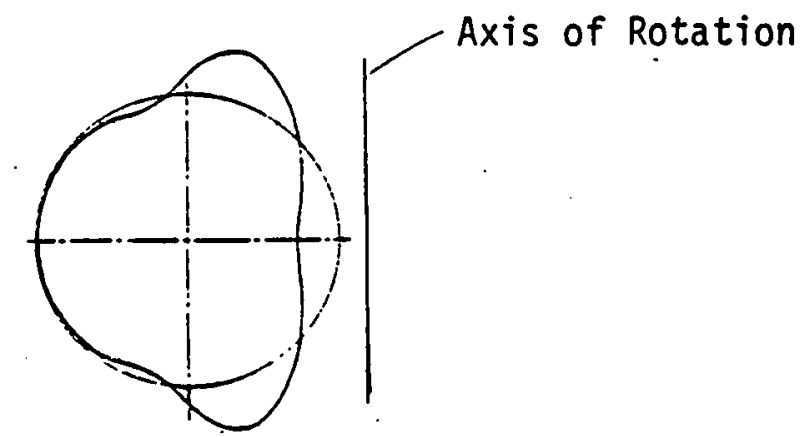

Symmetric Buckling Mode, $n=2$

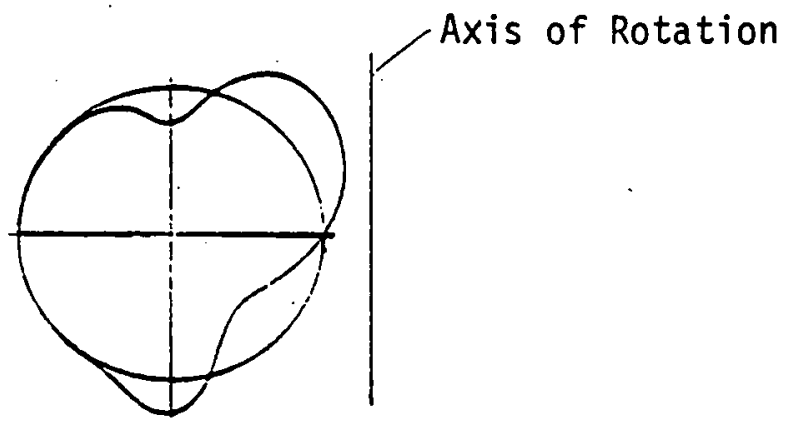

Asymmetric Buckling Mode, $\mathrm{n}=2$

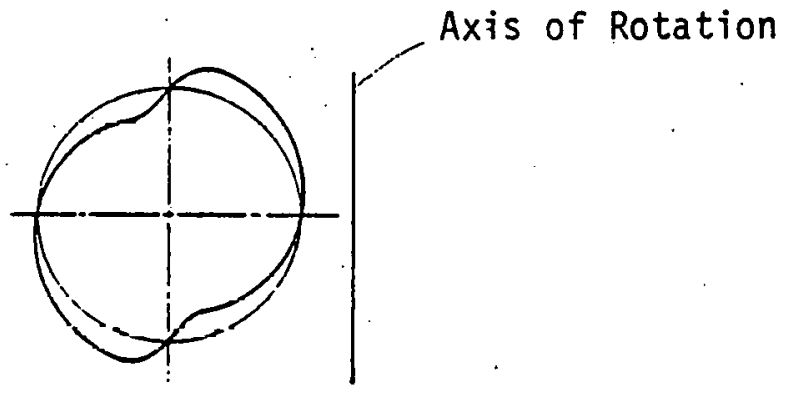

Asymmetric Buckling Mode, $n=0$

Figure 2-3. Possible Buckling Modes for a Toroidal Shell with a Circular Cross-Section 


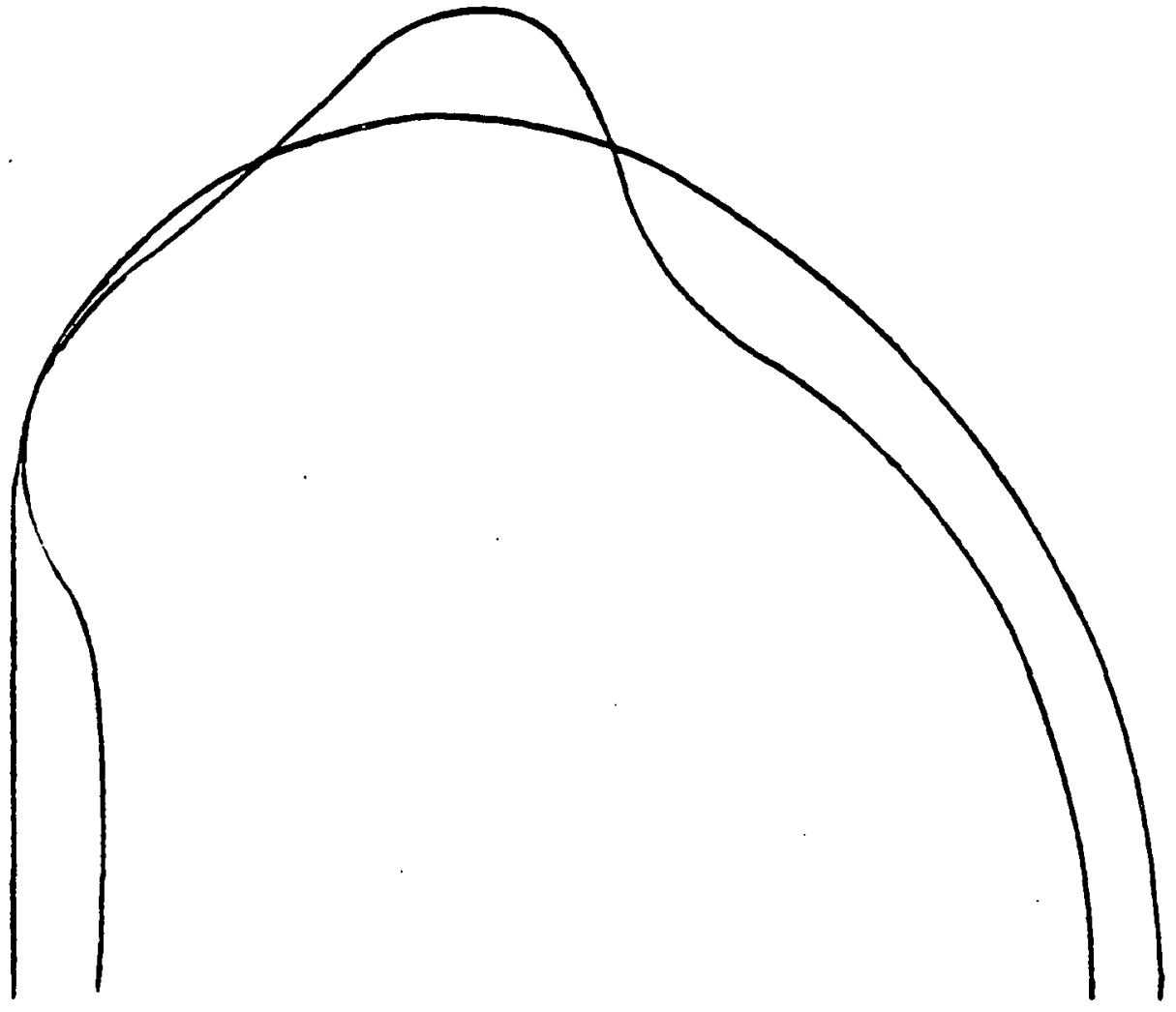

Figure 2-4. Preliminary Buckling Mode Geometry for the D Meridian Toroidal Shell 
circumferential waves; thus, reinforcing the assumption that the number of circumferential waves in the buckling mode for the monocoque shell will be $n=2$.

In comparing the results from the Sobel and Flügge analysis to two other known stability analysis techniques, one would find the following: the Sobel and Flüge method of analysis is appreciably more conservative than Maching $(7)$ and has critical buckling pressures very similar to Jordan ${ }^{(8)}$ for an asymmetric mode of failure. Also, Sobel and Flügge's experimental results were comparable to the results found from their theory. Thus, the stability analysis by Sobel and Flügge appears to be a viable technique for determining the critical buckling pressures for a circular toroidal shell.

\subsection{STABILITY ANALYSIS FOR A CYLINDRICAL SHELL}

The stability analysis of a cylindrical shell that is simply supported at its ends and subjected to uniform external lateral pressure has been investigated by many authors (see References 10, 11, 12, 13, 14).

The following is the stability equation ${ }^{(10)}$ where the critical pressure is minimized:

$$
\operatorname{Pcr}=\operatorname{En}\left[\frac{\left[(\pi r / L)^{2}+n^{2}\right]^{2}}{n^{2}} \frac{(h / r)^{2}}{12\left(1-v^{2}\right)}+\frac{(\pi r / L)^{4}}{n^{2}\left[(\pi r / L)^{2}+n^{2}\right]^{2}}\right]
$$

Where

$$
\begin{aligned}
& L=\text { Length of cylindrical shell } \\
& v=\text { Poisson's ratio } \\
& h=\text { Thickness of shell wall } \\
& r=\text { Radius of shell meridian } \\
& n=\text { Number of circumerential lobes } \\
& E=\text { Modulus of elasticity }
\end{aligned}
$$

For different values of $(h / a)$ and $(a / L)$ the critical buckling may occur at different $n$ values. In Figure 2-5, the buckling curves are illustrated for a straight cylindrical shell with a radius of $184 \mathrm{~cm}$ and $2 \measuredangle 3 \mathrm{~cm}$. The lengths 


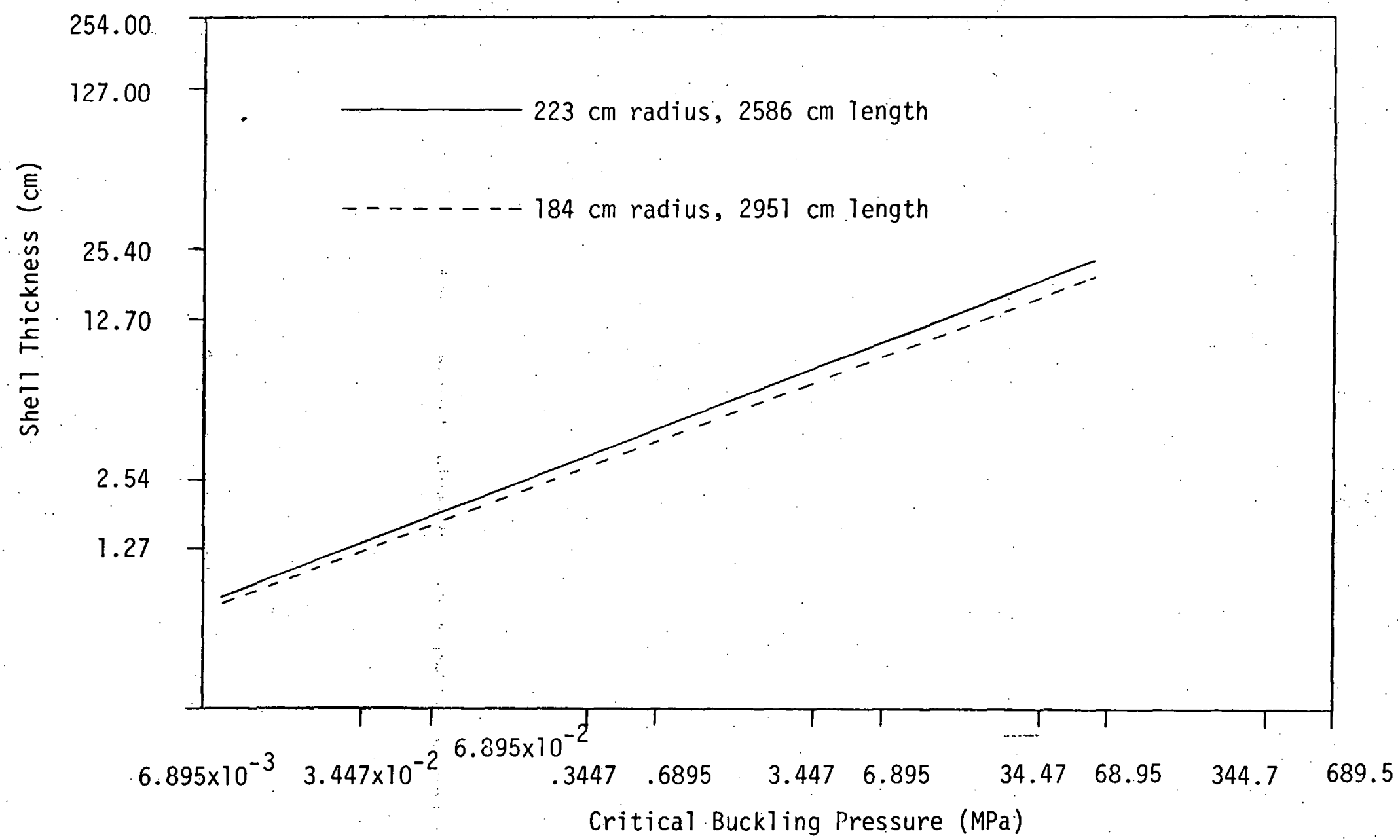

Figure 2-5. Buckling Curves for Straight Cylindrical Shells Having a Buckling Mode of $n=2$ 
of the straight cylindrical shells were assumed to have lengths that are equal to the centerline periphery of a circular torus.

For a cylindrical shell having a length of $2586 \mathrm{~cm}$ with a radius of $223 \mathrm{~cm}$, one will find that the buckling occurs at $n=2$ for a shell having a thickness greater than $1.27 \mathrm{~cm}$. For a shell thickness of $0.5 \mathrm{~cm}$ to $1.27 \mathrm{~cm}$, the number of circumferential lobes increases to 3 . As the shell decreases in thickness from $0.5 \mathrm{~cm}$, the number of circumferential lobes in the meridian continues to increase.

One would find approximately the same behavior from the other cylindrical shell investigated.

Also, it should be pointed out that the wall thickness of a finite cylindrical shell, which has a length that is equal to the periphery of a torus and has a radius of curvature equal to that of the torus meridian in a poloidal direction, is approximately double that for a torus at the same critical buckling pressure. This ratio tends to decrease at higher external pressures.

Theoretical buckling pressures of elliptic cylinders under normal pressure were obtained by using Goldenviezer's (15) linear, thin shell theory in conjunction with Calcrkin's method for solution by Yao and lenkins (16). The results, theory and test data agree, provided that the shell is thin and long.

For an elliptical cylinder with a semi-major axis of $208 \mathrm{~cm}$ and a semi-minor axis of $165 \mathrm{~cm}$, having a shell length equal to that of the torus meridian midpoint equator which is $2951 \mathrm{~cm}$, the following are from the findings of Yao and Jenkins ( for the critical buckling pressures for various shell thicknesses:

$$
\mathrm{Pcr}=\left\{\begin{aligned}
0.675 \mathrm{MPa} ; & 4.47 \mathrm{~cm} \\
0.248 \mathrm{MPa} ; & 2.79 \mathrm{~cm} \\
0.145 \mathrm{MPa} ; & 2.23 \mathrm{~cm} \\
27,580 \mathrm{~Pa} ; & 1.11 \mathrm{~cm} \\
2,413 \mathrm{~Pa} ; & 0.44 \mathrm{~cm}
\end{aligned}\right.
$$




\subsubsection{DISCUSSION}

The underlying theory used in all the buckling analysis referred to in this study has been the membrane theory. It is clear that the buckling equations for $a$. toroidal and cylindrical shell are different. Also, one would find that the buckling equations for a circular and elliptical cylindrical shell are quite different. Thus, it is obvious that the buckling analysis of a toroidal shell, in general, may not be compared to the solution for a cylindrical shell.

However, in comparing the critical buckling pressures of the elliptical cylindrical shell to the circular cylindrical shell, as shown in Figure 2-6, one finds some quantitative insight regarding the unique stiffness associated with each shel1. In examining the curves, one can reasonably state that the elliptic cylinder may be approximated for buckling analysis purposes by an equivalent circular cylinder. Particularly, this observation is representative in the load range that is of interest for this investigation.

My inclination at this point would be to make a conjecture that the critical buckiing pressure of the circular toroid, which has the meridian radius of $223 \mathrm{~cm}$, would have a comparable buckling curve to that of an elliptic meridian toroid having a meridian with a major axis of $208 \mathrm{~cm}$ and a minor axis of $165 \mathrm{~cm}$, especially in the low load range. If one was to accept this hypothesis, one could further conclude that the wall thickness of the elliptic portion of the $D$ shape meridian should be greater than $1.168 \mathrm{~cm}$ in order for a monocoque shell to be elastically stable for an external load of 101.356: Pa (1 atm).

Stancampiano ${ }^{(9)}$ concluded (in his stability analysis of the D meridian toroidal she11) that for an external pressure of $0.248 \mathrm{MPa}$, a minimum shell thickness of $1.65 \mathrm{~cm}$ is required for the shell to have elastic structural stability. "This identified set of data falls directly on the estimated stability curve for the elliptic portion of the D meridian in Figure 2-2.

\subsection{STABILITY ANALYSIS FOR CYLINDRICAL SHELLS OF VARIOUS STRUCTURAL ELEMENTS}

When one is confronted with the problem of designing a thin shell, it is well known that the simple monocoque unstiffened shell is structurally the least efficient mode of material disposition. for nonstabilized shells in compression. 


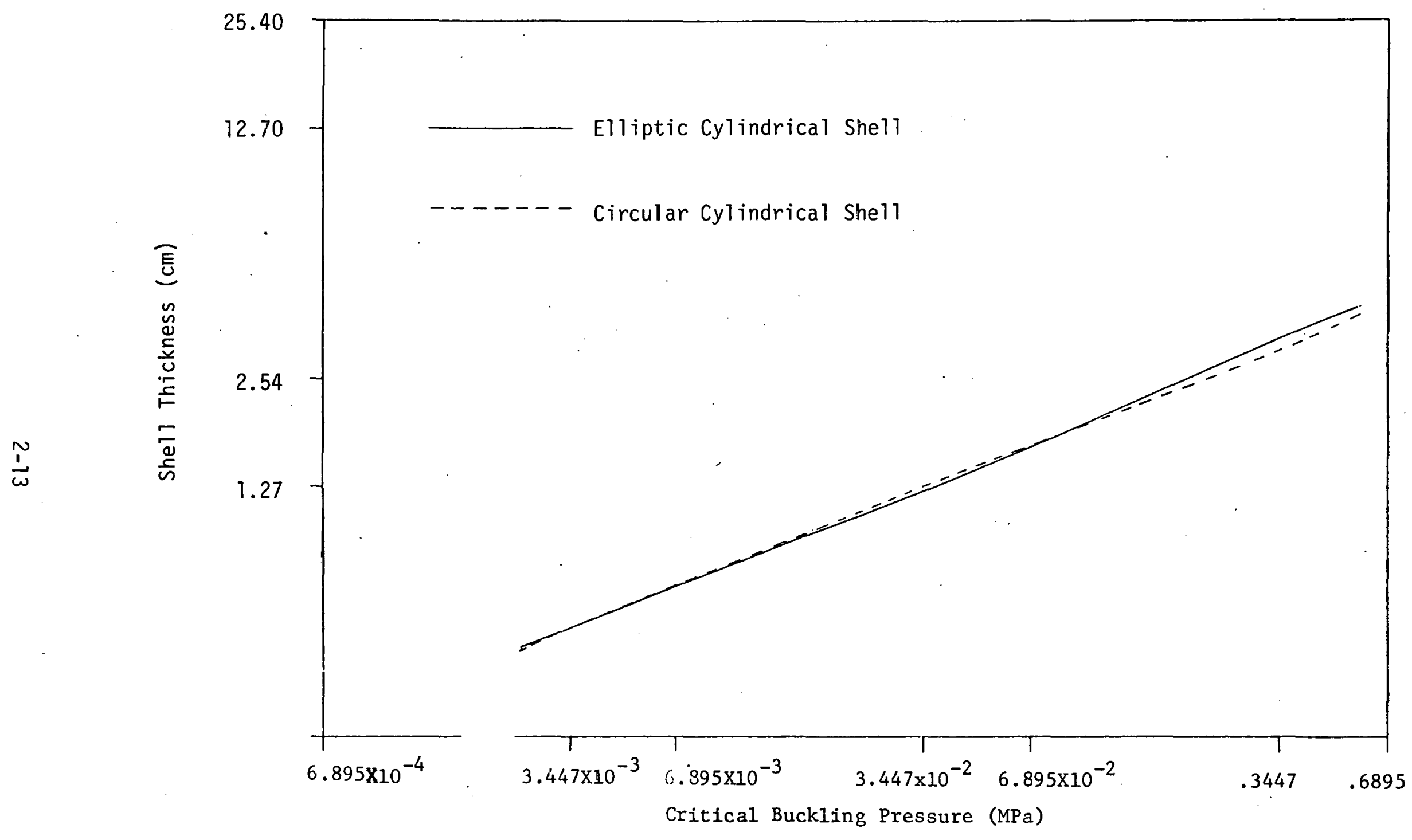

Figure 2-6. Buckling Curves for Elliptic and Circular Cylindrical Shells 
There are a number of techniques available which increase the shell's structural reliability and efficiency. In general, some of the methods available which avoid monocoque construction are as follows:

1. Sandwich construction

2. Conventional rib stiffening

3. Integral stiffening

\subsubsection{SANDWICH CYLINDRICAL SHELL}

Sandwich rib-cored shells are of interest for vacuum vessel applications, where shell buckling must be prevented at very high thermal and mechanical stress levels and where radial mass must be kept to a minimum. The sandwich element consists of two relatively thin faces, and ribs constructed of the same high-strength material as the skins. The sandwich construction shell is illustrated in Figure 2-7. The design objective is to obtain a structural element which is reliably strong and resists buckling due to thermal and mechanical loads, but at the same time is light in weight.

Previous investigations $(17,18,19,20,21)$ have identified the sandwich shell as having a much larger potential payoff in optimizing the weight-to-strength ratio than other reinforced shell structures. One problem which looms heavily in designing for sandwich construction, especially when severe thermal conditions are imposed upon the structure, is that of thermal stress and the technique of combining thermal stresses with load-induced stresses.

However, the sandwich cross-section provides the unique characteristic of being able to utilize the cavities of the core as the cooling channels to relieve the cored ribs and facesheets of their high thermal load. In a case such as this, where space. if of the essence, the efficient use of all the space within the structure is extremely important.

With all these desirable properties that can be obtained from the sandwich element, one may inquire why this type of structural element has not been more extensively used in the conceptual design schemes of fusion plasma containment vessel. It should be recognized that the sandwich shell theory is still dawning and buckling theories for sandwich shells differ significantly from that of the shell theory. 


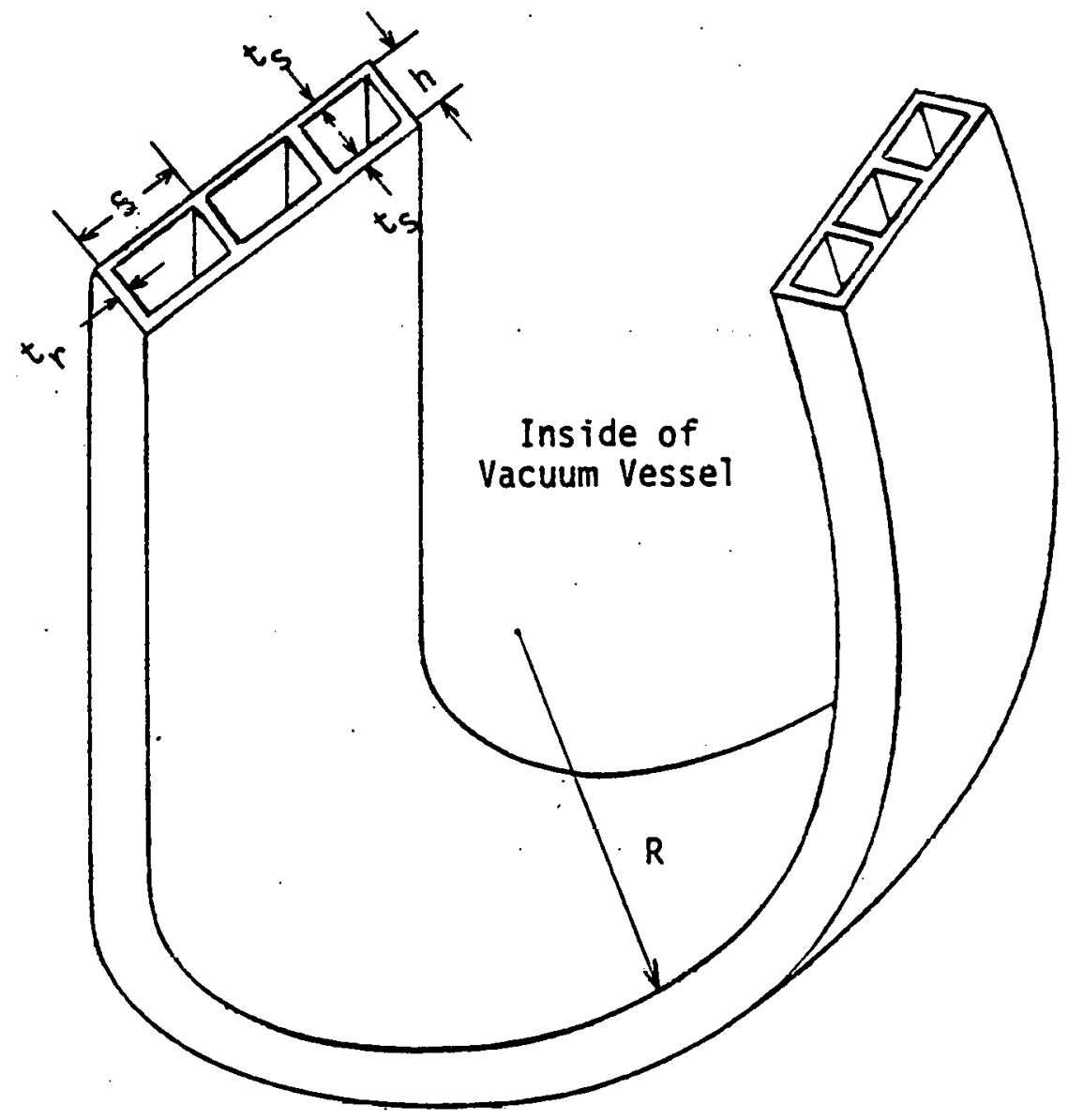

Figure 2-7. Sandwich Shell Section 
The concept of sandwich structures is not new. In fact, it has long been recognized as an efficient design to obtain a light weight compressive member. The reason its use has been limited is because of the extreme cost and difficulties in manufacturing such a structural element. Due to the recent improvements in manufacturing techniques, the element is becoming more economically feasibile, and the desirability of having more research data in this field is of extreme importance. The General Atomic Company has proposed a first wall concept which has structural characteristics similar to those of a sandwich first wall vessel. Their concept is to have "split tube" coolant channels chem-milled into a solid backwall with a first wall (skin) welded to the channeled back wall.

There is one area of sandwich structures where theory is well established in terms of design application, that being the flat sandwich plates which are used extensively in aircraft and related space vehicle technologies. The area of sandwich shells is less defined in general theoretical treatment. A good deal of work that has been done is research sponsored by the Office of Naval Research. This research was directed towards sandwich cylinders subjected to external hydrostatic pressure, simulating the conditions of the hull of a submerged submarine.

Other than the work of these endeavors, it is felt that investigation into the theoretical behavior of sandwich structures and shell is still undefined.

In examining Figure 2-7, it is obvious that the critical buckling pressure depends upon a number of parameters such as the spacing and dimensions of the web, $t r, s, h$, and also the thickness of the face sheets, $t_{s}$. Optimization of these parameters would yield a design where the maximum amount of strength for a structure has been reached for the least amount of weight. At this point, an efficient design results and the optimum proportions of the sandwich shell have been identified. Fulton's(21) thesis addressed the specific area of sandwich shell optimization for cylindrical shells under hydrostatic pressure. He determined that for a given case there exists a range of shell core parameters which, for all practical purposes, have the same strength-to-weight ratio. He identified 
his findings as the optimum range, and presented them for a number of sandwich she11 parameters.

For stability analysis purposes, the radius of the cylindrical shell is 223 centimeters with the sandwich shell having a length of 2586 centimeters. (It was noted in the previous section that a cylindrical she 17 with a radius of 223 centimeters and a length of 2,586 centimeters closely approximated the stability for an elliptic cylindrical shell which has dimensions that represented the elliptic portion of the D meridian. Also, the cylindrical shell's buckling curves predicted wall thickness approximately twice that of a toroidal shell with similar geometric parameters for the same external loads. Thus, using such an approximation is conservative.)

The following table 2-1 summarizes four possible sandwich cross sections which would be representative of a TNS sandwich shell. The dimensions were determined using Fulton's optimization curves ${ }^{(21)}$ for the sandwich shells and also the following formulation where $P$ critical is calculated.

$$
\operatorname{Pcr}=2 \sigma_{c r}(h / R)(t s / h)\left(1+1 / 2\left(\frac{h}{t s}-1\right)\left(\frac{t r}{s}\right)\right)
$$

For analysis purposes, the $h / R$ parametcr and the yield point of the material, $\sigma_{\mathrm{Cr}}$ which was assumed to be $68.95 \mathrm{MPa}$, were held constant.

TABLE 2-1

OPTIUM DIMENSIONS FOR A SANDHICH VACUUR VESSEL

$\operatorname{Pcr}\left\{\begin{array}{llllll}0.132 \mathrm{MPa} & 7.44 \mathrm{~cm} & \frac{\mathrm{ts}}{0.185 \mathrm{~cm}} & \frac{\mathrm{tr}}{0.091 \mathrm{~cm}} & \frac{\mathrm{s}}{12.4 \mathrm{~cm}} \\ 0.168 \mathrm{MPa} & 7.44 \mathrm{~cm} & 0.247 \mathrm{~cm} & 0.249 \mathrm{~cm} & 18.6 \mathrm{~cm} \\ 0.238 \mathrm{MPa} & 7.44 \mathrm{~cm} & 0.371 \mathrm{~cm} & 0.185 \mathrm{~cm} & 49.5 \mathrm{~cm} \\ 0.482 \mathrm{MPa} & 7.44 \mathrm{~cm} & 0.744 \mathrm{~cm} & 1.115 \mathrm{~cm} & 124.1 \mathrm{~cm}\end{array}\right.$

Figure 2-8 illustrates how the shell's cross-sectional area of the sandwich element increases with respect to the increasing buckling pressure. 


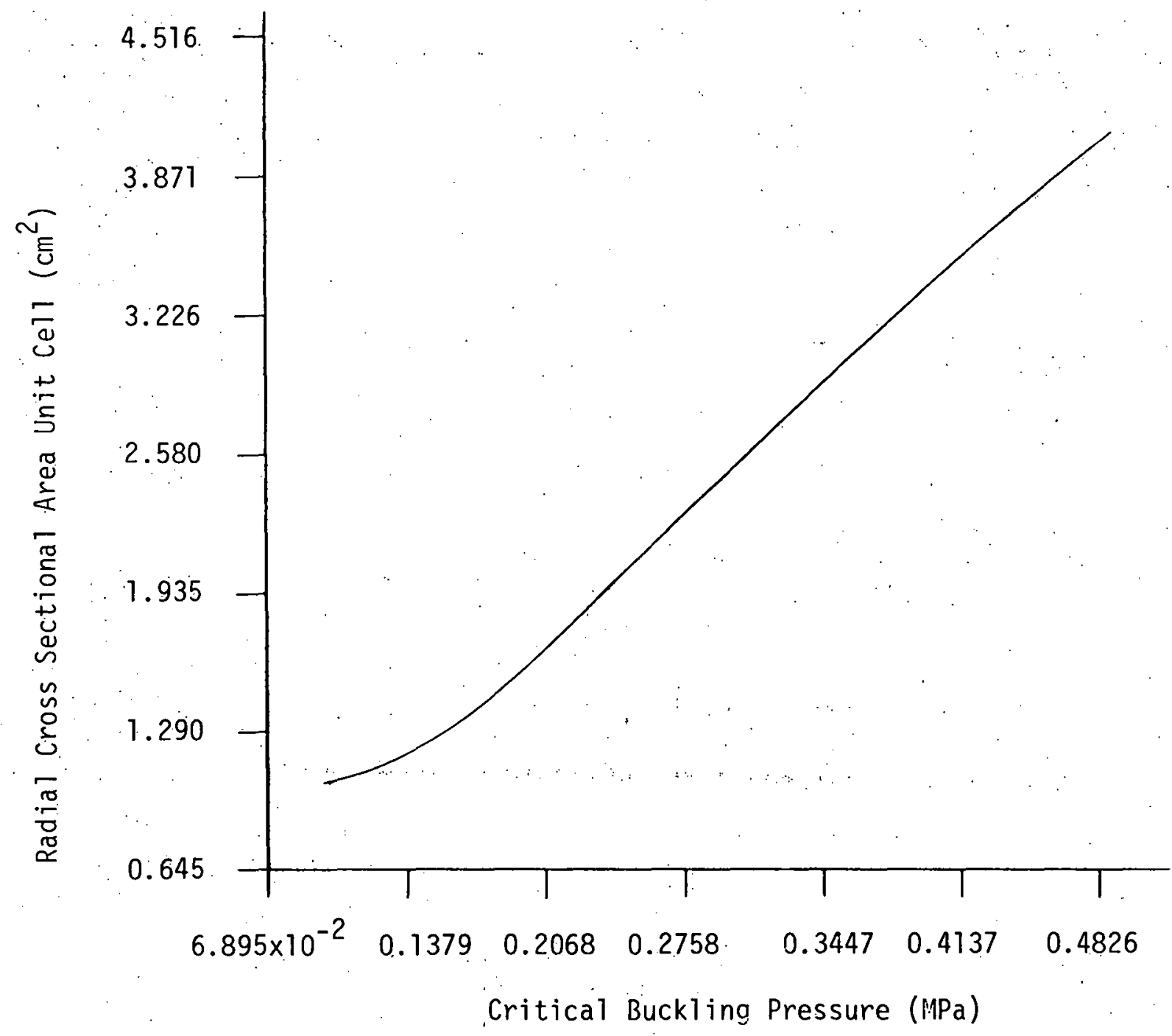

Figure 2-8. Sandwich Shell's Radial Cross-Sectional Area Versus Critical Buckling Pressure 


\subsubsection{RIB-STIFFENED CYLINDRICAL SHELL}

The rib-stiffened shell is illustrated in Figure 2-9. Buckling analysis for the rib-stiffened cylindrical shell has been investigated by a number of authors $(22,23,24,25)$. These studies have presented calculations for determining the critical buckling pressure for panel buckling as well as general instability of shells evenly stiffened by ribs with equal spacing. Elastic buckling between stiffeners will be the assumed mode of failure. This mode of failure occurs usually in a large number of circumferential lobes $\left(n^{2}>1\right)$.

The following equation from Saunder's and Windenburg's ${ }^{(24)}$ work calculates the needed thickness of a shell, $t$, which will provide shell stability for a specified external pressure, $p$, over an unsupported length, L.

$$
\begin{gathered}
t=\left(d \frac{P L / d}{K}\right)^{0.40} \\
\text { where } k=2.28 E\left(\frac{m^{2}}{m^{2}-1}\right)^{0.75} ; \text { and } m=\frac{1}{v}
\end{gathered}
$$

The previous equation can be used to specify the correct thickness of the she11 which is reinforced by stiffening ribs spaced to suit design conditions.

In determining the number of lobes, $n$, which cause the collapsing pressure to be a minimum for agiven $t, L$, and $p$, one can use Saunder's and Windenburg's (24) findings.

$$
n=\left(\frac{7.06}{\left(\frac{L}{d}\right)^{2} \frac{t}{d}}\right)^{0.25}
$$

To calculate the required moment of inertia of the stiffening rings, which are 20 percent stronger than the she11, the formula obtained from Saunders and Windenburg ${ }^{(24)}$ is as follows:

$$
\text { I stiffener }=\frac{0.4 r^{3} L}{E} P
$$




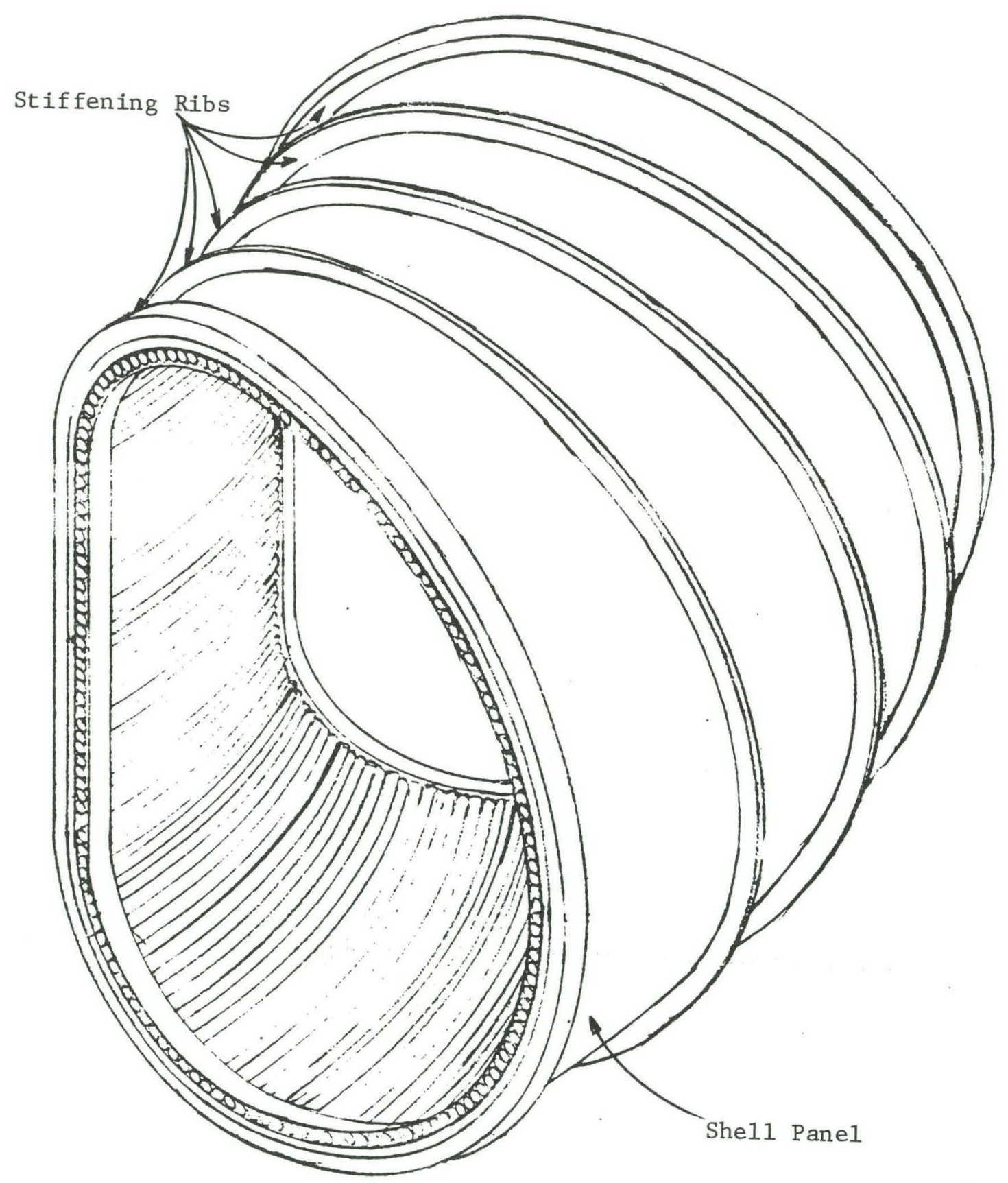

Figure 2-9. Rib-Stiffened Shell 
The stiffener may take on a number of forms. A few possible forms are illustrated in Figure 3-10. The stiffeners can be either internal or external.

If the stiffeners are designed for internal support, they can simply rest against the shell. External stiffeners must be rigidly connected by welding or other means so that the stiffeners deflect with the shell under load.

Figure 2-11 11 lustrates shell panel thickness versus various unsupported panel lengths. Theses curves were generated for five different external pressures. Figure 2-12 shows the needed area moment of inertia of the stiffener for the various panel lengths and external pressures.

The importance of designing the correct sized stiffener to accommodate the shell's panel should be emphasized. The wall of the vessel contracts nearly uniformly under external pressure until the elastic limit of the material is reached. Any stiffeners, penetrations, or attahcments which prevent the shell from contracting in this manner would most likely induce unnatural deformations, the equivalent of eccentric loading acting on the she11. Thus, the paradox being that frames which are too stiff may result in a reduction of collapsing pressure. The most efficient stiffened design is one that has structural members that are just strong enough to carry the designed collapsing pressure.

\subsubsection{INTEGRALLY STIFFENED SHEI.L}

The integrally stiffened shell is illustrated in Figure 2-13 which shows a stiffener configuration resembling a waffle pattern. This structural element has had limited industrial use since the cross-section is very difficult to handle analytically, thus causing problems in efficiently designing and optimizing stiffener size and configuration. Also, this configuration represents a fabrication challenge.

Utilizing the integrally stiffened shell for vessel purposes with the imposed high thermal loads would induce high thermal gradients, causing excessive thermal stresses. These limitations point out the inadequacy of trying to implement an integrally stiffened shell in a plasma containment vessel. Thus, further invcstigation is not warranted. 


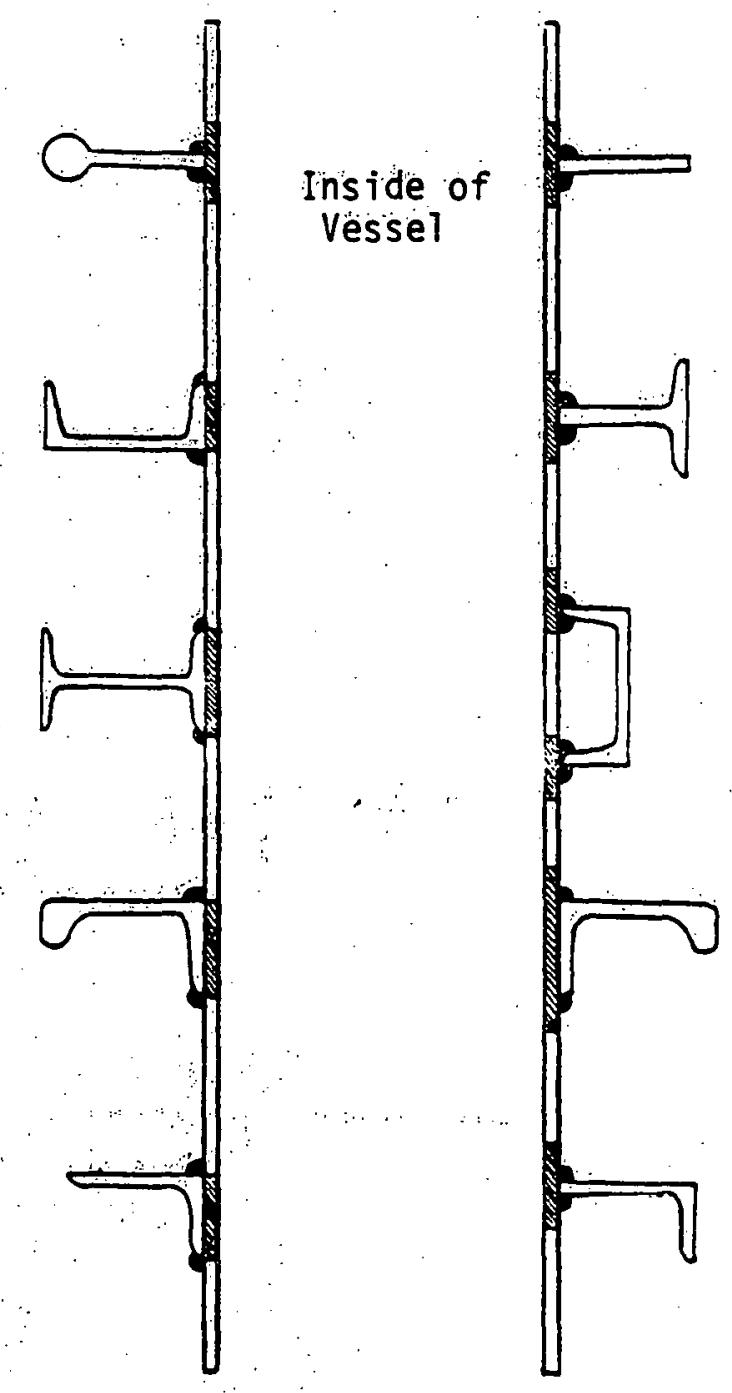

Figure 2-10. Various Stiffening Forms 


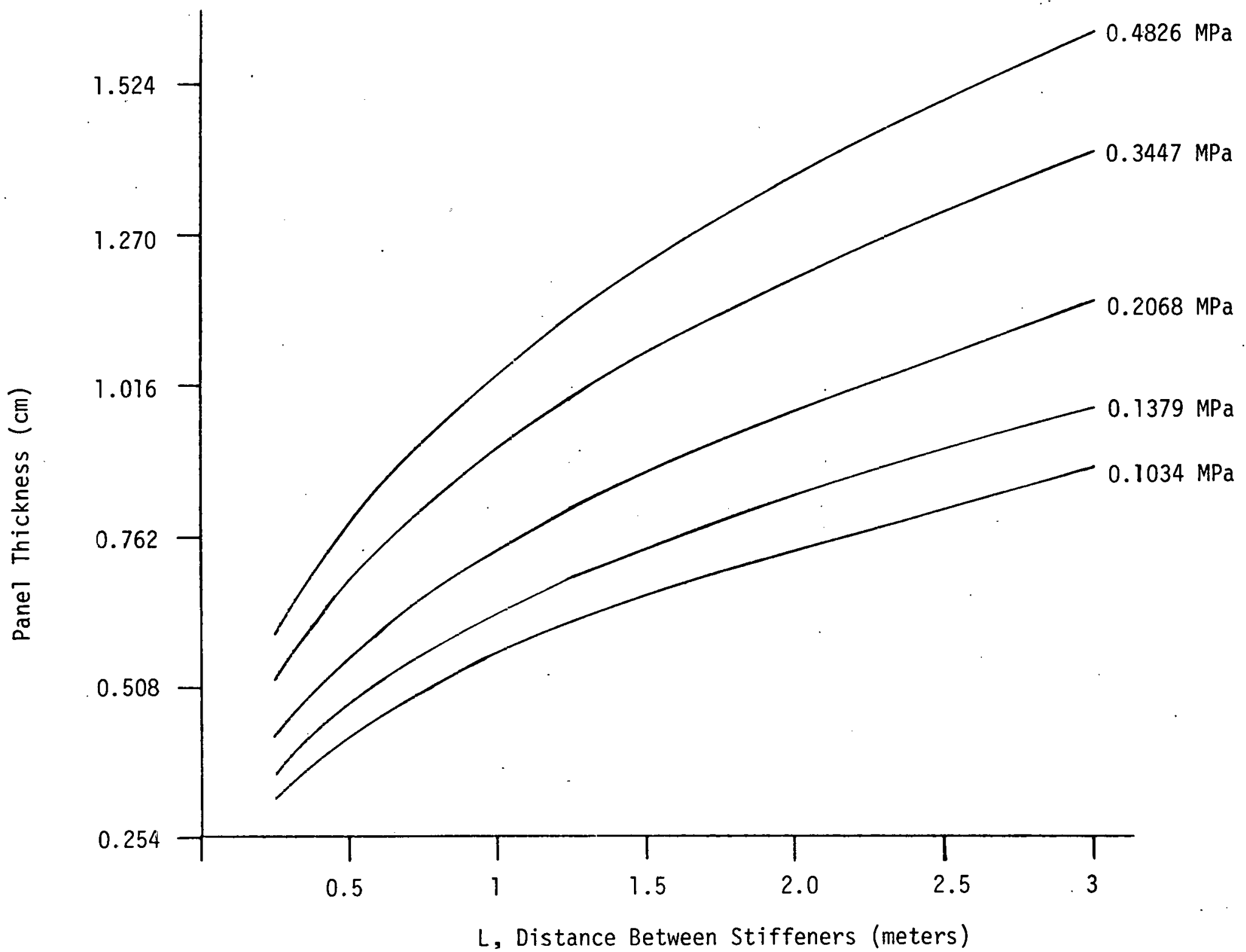

Figure 2-11. Stiffener Spacing Versus Panel Thickness for Various External Pressures 


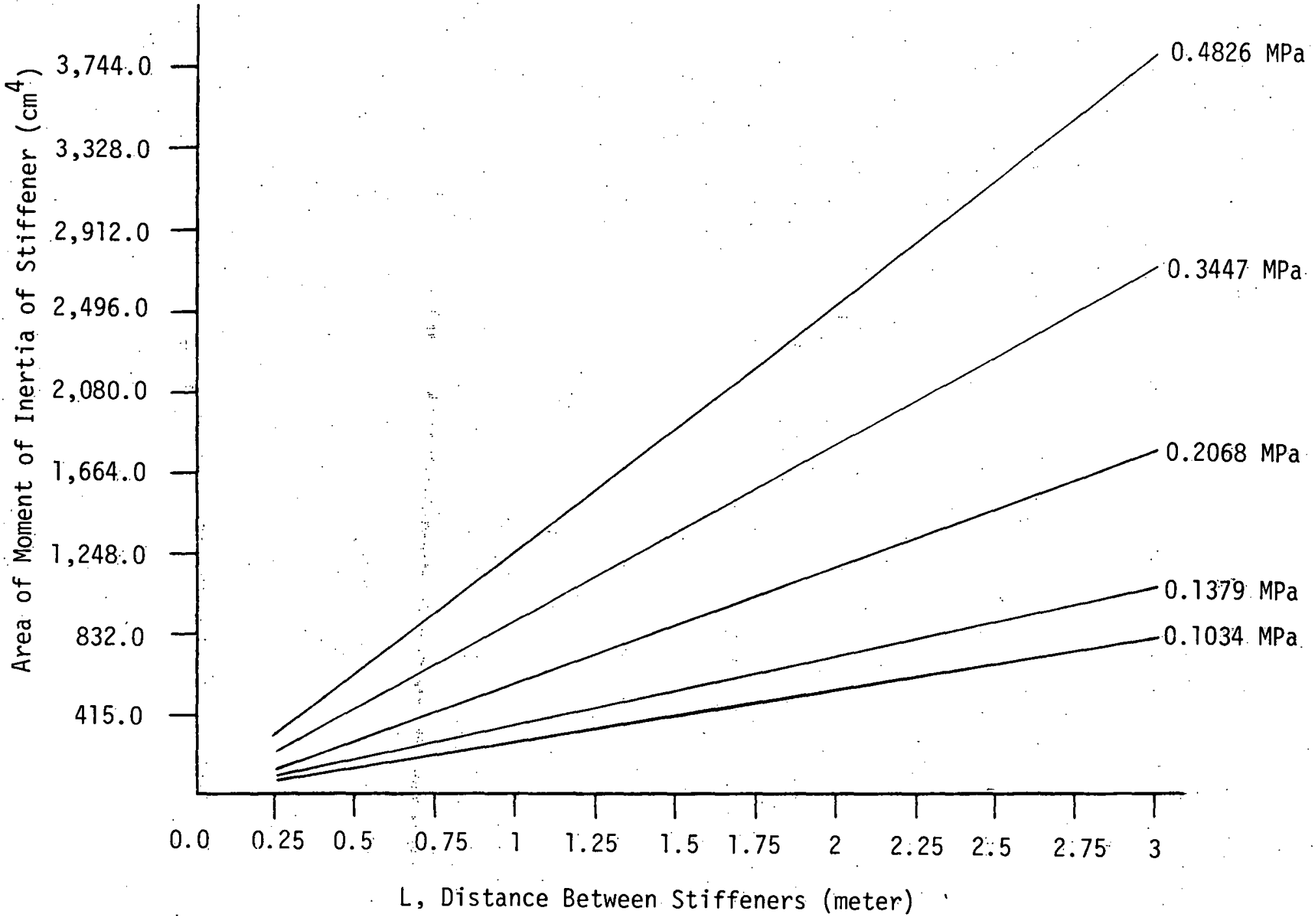

Figure 2-12. Needed. Area Moment of Inertia of the Stiffener for Various Panel Lengths and External Pressures 


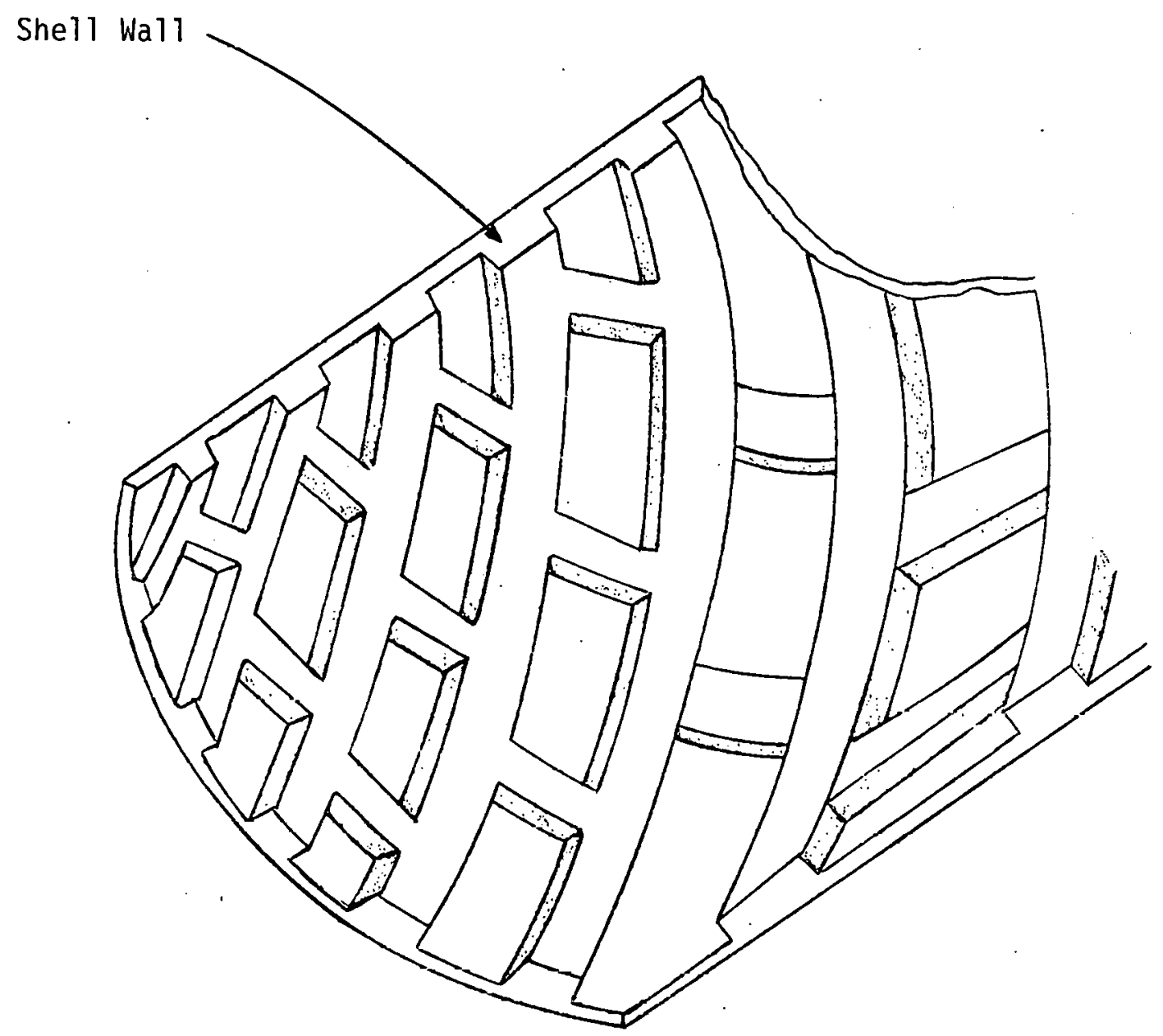

Figure 2-13. Integrally Stiffened Shell 


\subsection{CONCLUSIONS}

In summarizing the potential alternatives one has available to satisfy the design conditions for the TNS Vacuum Vessel, it is necessary to reiterate the design objectives for the vessel. The design objectives are to, cool the vacuum vessel below or near $500^{\circ} \mathrm{C}$ with minimal pumping power. The $500^{\circ} \mathrm{C}$ metal temperature is the threshold above which the maximum allowable stress of the material deteriorates rapidly. The structure should be designed in such a way that the heating and cooling is as uniform as possible. From the viewpoint of optimum neutron utilization, the radial mass of the structure should be a minimum. Also, the feasibility of shell manufacturing must be considered.

Figure 2-14 shows the curves for radial area versus external load for three different structural elements. It is obvious that the simple monocoque shell is the least efficient structural element in terms of mass utilization. The rib-cored sandwich shell appears to be approximately $60 \%$ more efficient in mass utilization than the rib-stiffened shell for low external loads. It should be pointed out that the rib-stiffened curve is based upon unstiffened panels having lengths of 1 meter. Also, the area moment of inertia of the stiffener was not optimized in regard to finding the optimum mass efficient stiffener. It is clear that these parameters have direct bearing on the illustrated rib-stiffener shell curve in Figure 2-14. Thus, the potential exists for the rib-stiffened shell to demonstrate a higher efficiency in radial mass utilization. Figure 2-14 illustrates that the sandwich structural element is the most efficient method of mass deposition in the lowest load range. However, such a cross-section has a number of drawbacks associated with its intended application. There is a high degree of uncertainty with respect to the reliability of the weld metal under such severe radiation, thermal, and stress conditions as the base metal. Under such conditions, the austenitic stainless steel is susceptible to intergranular stress corrosion cracking. Fabrication of the sandwich shell requires extensive welds. Also, combining the mechanical and thermal loads, as the sandwich shell does, will tend to induce thermal deformation of the shell. And finally, the cooling scenario for a sandwich shell would be more involved than the proposed schemes for the other shells. with the pumping power being excessive since helium gas would be the coolant medium for the sandwich shell. 




Figure 2-14. Radial Cross-Section Area Versus Critical Buckling Pressure for Various Shell Structural Elements 
Based upon these stability findings, the rib-stiffened shell appears to be the most viable approach.

It should be noted that the buckling pressures obtained in this chapter are based upon a number of assumption. Buckling pressures of the circular toroid are evaluated from published literature ${ }^{(5)}$. Other results presented in this section were based upon extrapolations; even though the results appear to be reasonable, one must be cautioned on their level of accuracy. 


\subsection{STRESS ANALYSIS OF THE VACUUM VESSEL}

In this section, an attempt is made to calculate the stresses acting from the deadweight of the evacuated toroidal shell hung from the top and the stresses from the external pressure acting on the shell. These stresses are significant and must be considered for design purposes.

\subsection{STRESS ANALYSIS OF THE MONOCOQUE SHELL}

As was the case for the buckling analysis for the $D$ cross-sectin torus, there is also no general analytical treatment for calculating the stresses and displacement for the $D$ cross-section torus. Therefore, one must implement various techniques to resolve this problem.

There have been a limited number of investigations to determine the stresses and displacements of toroidal shells with elliptic cross-sections. Lorenz was one of the first to address this problem. His findings give the meridian stresses for an elliptic cross-section torus with normal external pressure acting on the she1l. It. is nbvious that the membrane solution is limited in application since the stresses are determined by neglecting the effect of bending acting in the shell. walls.

Lorenz's findings were expanded upon by a number of other investigators (26) who solved the problems of an elliptic cross-section toroidal shell loaded by uniform normal external wall pressure, and also an open shell subjected to end bending moments. In their work, they determined the conditions under which the membrane theory gives a good approximation to the actual stress distribution and where the membrane theory doesn't hold true; the torus should be treated analytically as a straight cylindrical tube, and also when neither of the two limited analyses applies.

For a toroidal shell of elliptical cross-section, with dimensions which are representative of the TNS, the membrane solution is applicable. The membrane 
stresses are found by the following equations:

$$
\begin{aligned}
& \sigma \theta=-\frac{b P}{t}\left(\frac{1+(\lambda / 2) \sin \theta}{1+\lambda \sin \theta}\right)\left(1-e^{2} \cos ^{2} \theta\right)^{1 / 2} \\
& \sigma \phi=-\frac{a P}{t}\left(\frac{e^{2} \sin \theta(1+\lambda \sin \theta)+(\lambda / 2)(b / c)^{2}}{\left(1-e^{2} \cos ^{2} \theta\right)^{7 / 2}}\right)
\end{aligned}
$$

Where

$$
\begin{aligned}
& e^{2}=1-(b / c)^{2} \\
& \lambda=b / a \\
& a=\text { Toroidal axis of rotation } \\
& b=\text { Semi-minor axis } \\
& c=\text { Semi-major axis }
\end{aligned}
$$

The maximum meridian stress will occur at - $\pi / 2$ and the maximum toroidal stress acts àt $\pi / 2$.

$$
\begin{aligned}
& \sigma \theta(\max )=-\frac{b P}{h}\left(\frac{1-\lambda / 2}{1-\lambda}\right) \\
& \sigma \phi(\max )=-\frac{a P}{h}\left(e^{2}(1+\lambda)+(\lambda / 2)(b / c)^{2}\right)
\end{aligned}
$$

Figure 3-1 illustrates the variation of the meridian and toroidal stresses for the elliptic monocoque toroidal shell having a thickness of $1.16 \mathrm{~cm}$. The membrane stresses from the atomospheric pressure acting on the evacuated shell are relatively sma 11 .

The maximum bending stresses resulting from continuous support at the top of the toroid are determined by ring approximation. The external forces considered are from the dead weight of the shell and the reaction forces at the point of support for the shell. 


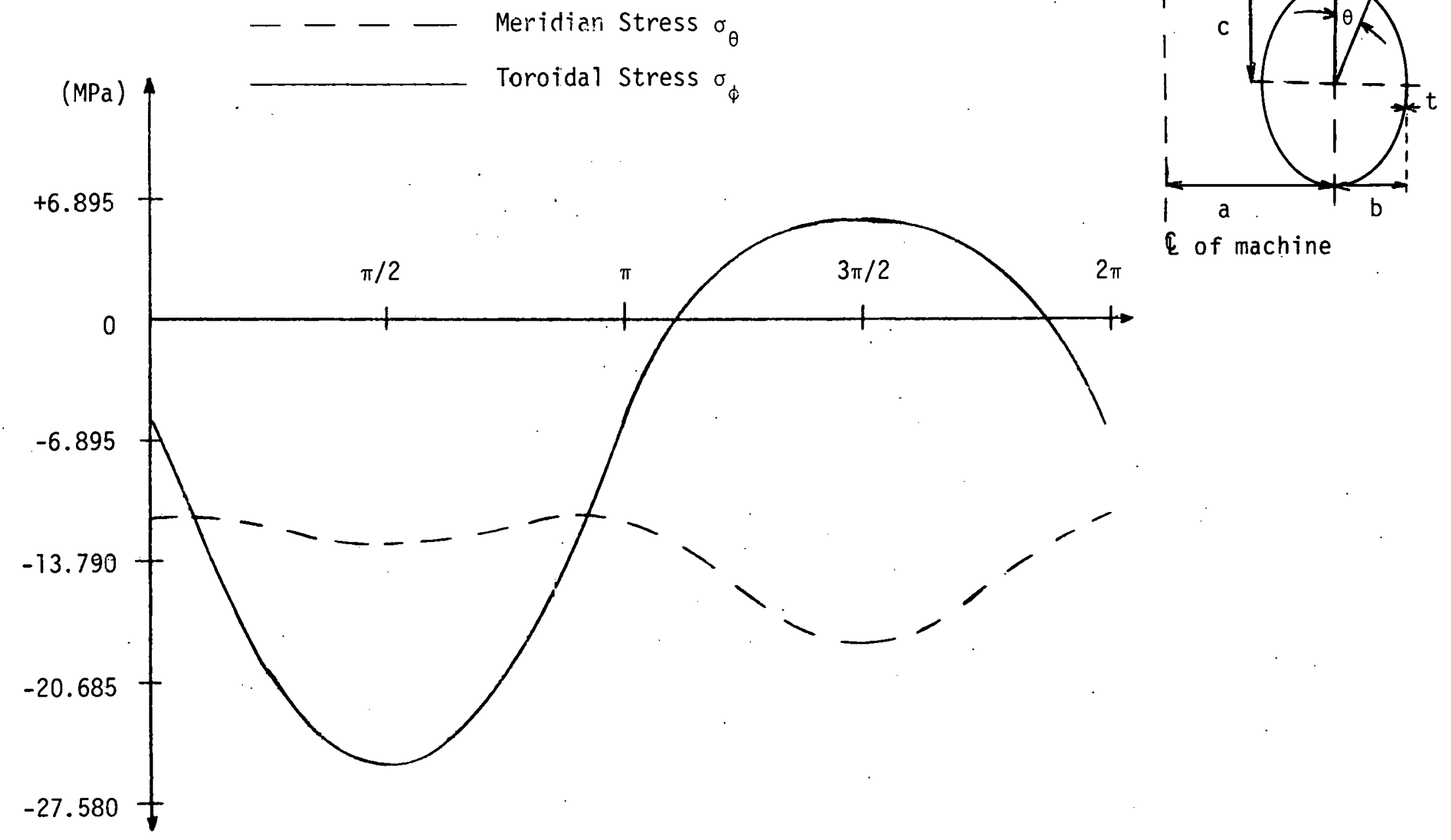

Figure 3-1. The Meridian and Toroidal Stresses for the Elliptic Toroid Under Uniform External Pressure 
It is realized that this technique is conservative for approximating the bending stresses in the torus. However, it still provides a meaningful approximation for the needed shell thickness to support the dead weight of the shell.

For an elliptical ring under equal and opposite forces at the extremities of the major axis, the maximum bending moment is approximated in the book by Roark $(27)$.

The following equation calculates the maximum bending stress acting at the point of support:

$$
\sigma_{\theta}(\max )=\frac{6 K Y \text { Le } a}{t}
$$

Where $K$ is a coefficient which depends on the ratio of $a / b$ and

$$
\begin{aligned}
& a=\text { Semi-major axis } \\
& b=\text { Semi-minor axis } \\
& \text { Le }=\text { Perimeter of ellipse } \\
& \gamma=\text { Uniform weight per unit area } \\
& t=\text { Thickness of the shell }
\end{aligned}
$$

Figure 3-2 illustrates the maximum hoop stress versus shell wall thickness. For the proposed thickness of $1.16 \mathrm{~cm}$ (the shell wall thickness sized from buckling analysis), the maximum stress occurred at the supporting point of the toroid will exceed the yield stress of the shell. A safe shell thickness should be greater than $2.5 \mathrm{~cm}$.

\subsection{STRESS ANALYSIS OF RIB STIFFENED SHELL}

It's apparent, from the monocoque shell stress analysis, that the in-plane bending stress caused when the shell is continuously supported from the top is significant. The previous section illustrated that the radial wall mass of the rib stiffened shel1 is approximately 30\% of the required wall mass for the monocoque shell for stability purposes. This reduction in wall mass will have significant bearing on the magnitude of the bending stresses induced in the region where the vacuum vessel is supported. 


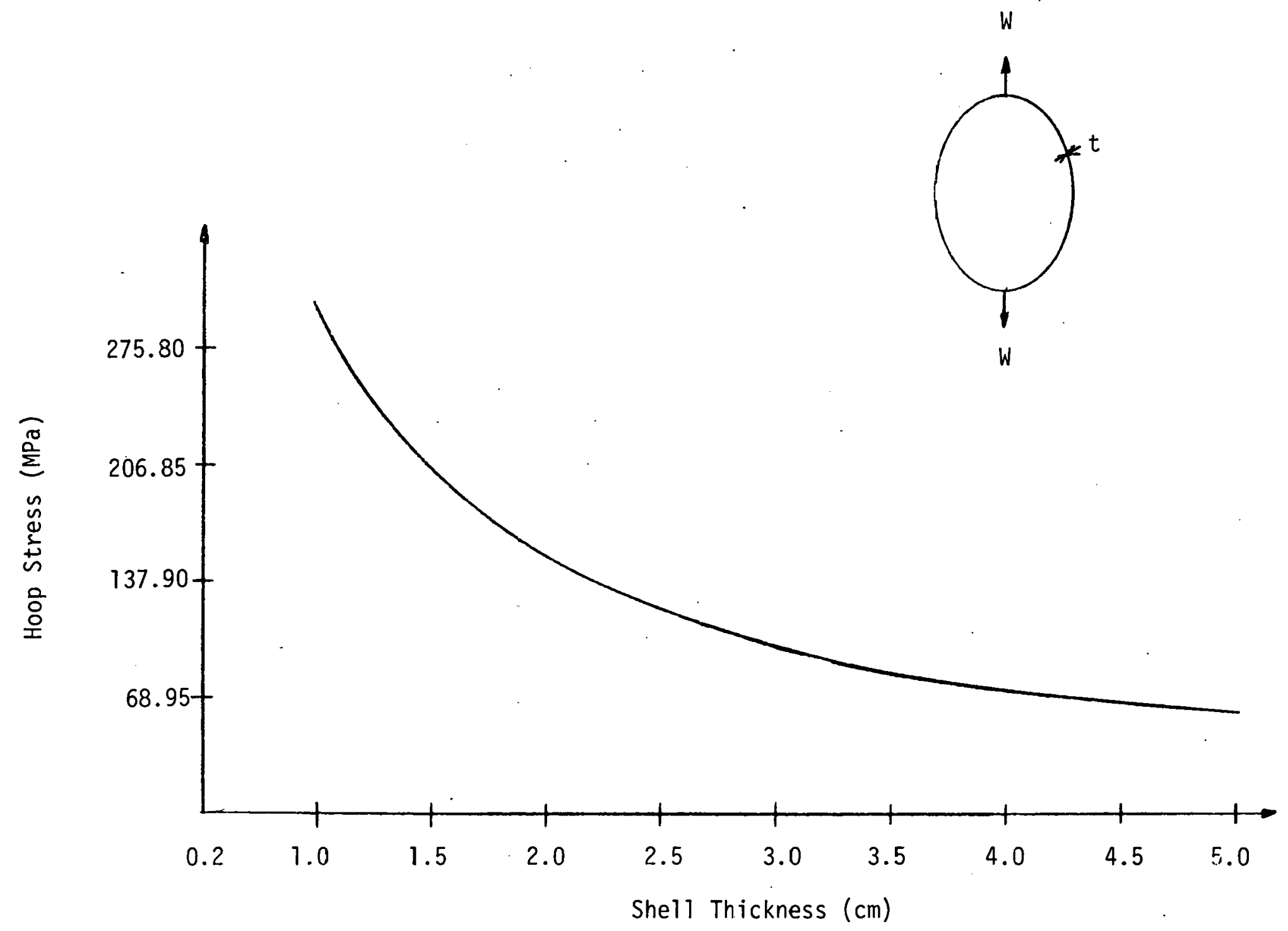

Figure 3-2. Hoop Stress Versus Shell Wall Thickness for Stresses Induced from Continuous Support of a Monocoque Shell 
Flügge ${ }^{(28)}$ found the stresses, in an open elliptic cylinder that is simply supported at the ends by stiffening rings, induced from the shell's weight. The three stress results resultants acting in the elliptic cylinder are as follows:

$$
\begin{aligned}
& N \phi=-\frac{\gamma a^{2} b^{2} \cos \phi}{\left(a^{2} \sin ^{2} \phi+b^{2} \cos ^{2} \phi\right)^{3} / 2} \\
& N \times \phi= 1 / 2 \gamma(L-2 x) \frac{2 b^{2}+\left(b^{2}-a^{2}\right) \cos ^{2} \phi}{b^{2} \sin ^{2} \phi+a^{2} \cos ^{2} \phi} \\
& N x=\frac{r x(L-x)}{2 a^{2} b^{2}}\left(1-3 b^{2} \frac{a^{2}-\left(b^{2}-a^{2}\right) \sin ^{2} \phi}{\left(b^{2} \sin ^{2} \phi+a^{2} \cos ^{2} \phi\right)^{2}}\right) \frac{\cos \phi}{\left(b^{2} \sin ^{2} \phi+a^{2} \cos ^{2} \phi\right)^{1 / 2}}
\end{aligned}
$$

Where $\gamma=$ Uniform weight per unit area.

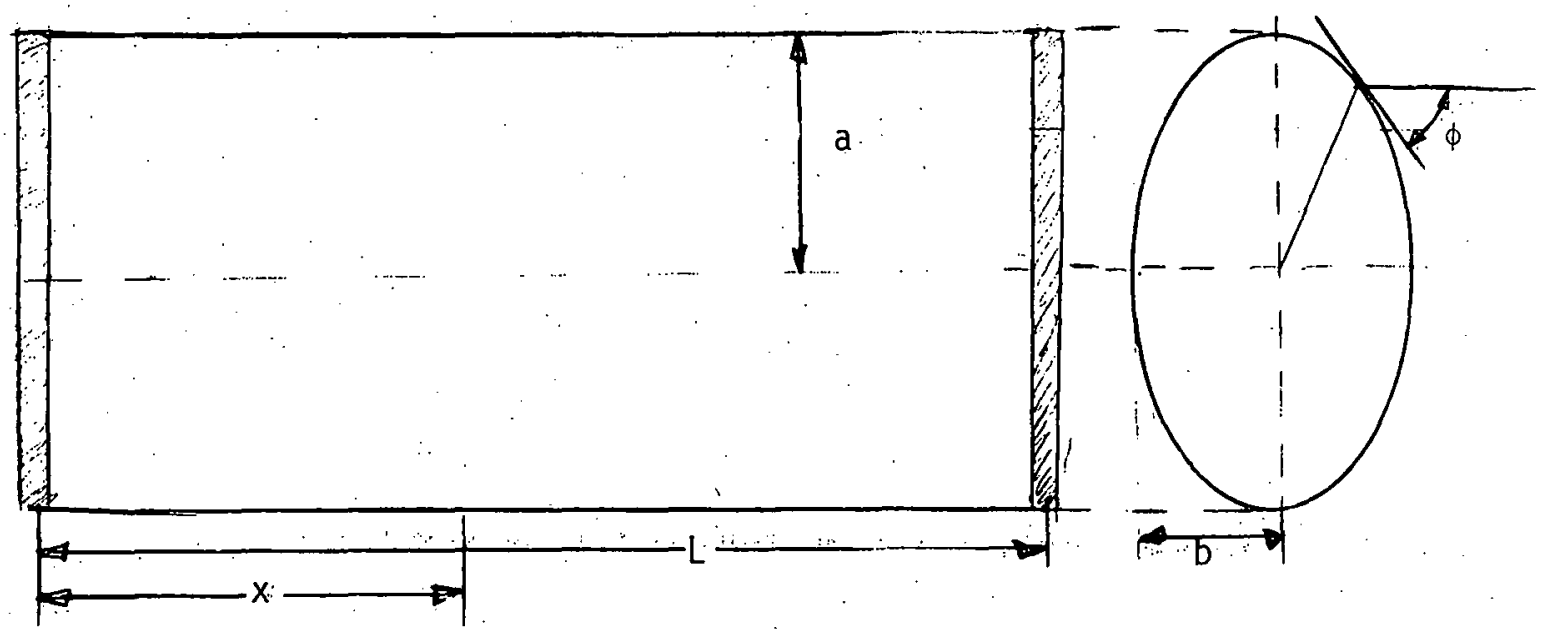

The angle $\phi$ is measured between a local tangent plane and a fixed horizontal plane.

It was found that the sum of these stresses induced from the shell's weight are negligible for such a short thin shell.

In determining the stresses in a uniform wall of elliptical cross-section for a rib.stiffened cylinder subjected to a uniform external pressure, one must 
model the problem by numerical methods. The available papers which address an elliptic cylinder, in general, make assumptions to solve the indeterminate problem which do not apply directly to the rib-stiffened elliptical cylinder. Also, the formulation does not account for the added stiffness from the supporting $r i b s$. Thus, the available literature is inadequate in handling this specific case.

Since the shell thickness and panel length were sized from stability analysis, one can assume that the stresses in the shell due to the external pressure are within the allowable yield limit of the material. This was found to be true for the monocoque shell which has a thickness sized from stability analysis, where the external pressure induced stresses were relatively small and well below the yield limit of the material.

The reference method of support for the rib-stiffened torus is to hang the shell from the stiffening ribs. The bending stresses induced in the stiffening ribs from the imposed load of the rib and unsupported shell needs to be calculated. These bending stresses will be determined by ring approximation. The maximum stress will occur at the support area of the rib; this point being the horizontal tangent of the elliptical rib. (This proposed location of support is the most inefficient method of suspension; thus the results are conservative.) The maximum bending moment can be calculated by an apprnximate method found in Roark ${ }^{(27)}$.

The following equation calculates the maximum bending stress acting at the point of support:

$$
\sigma_{B(\max )}=( \pm) \frac{10.76(\text { in. }) W(1 \mathrm{~b}) \mathrm{h}(\mathrm{in})}{I\left(\mathrm{in}^{4}\right)} 1,2
$$

where $h_{2}$ would yield the maximum compressive stress and $h_{1}$ the maximum tensile stress.

For an unsupported panel length of 1 meter, the approximate weight of the rib and shell is approximately $900 \mathrm{kgs}$. A cross-section of a potential coolant manifold stiffening rib which has the required area moment of inertia of its centroidal axis, parallel to the shell, of $250 \mathrm{in}^{4}$ is illustrated in Figure 3-3. 


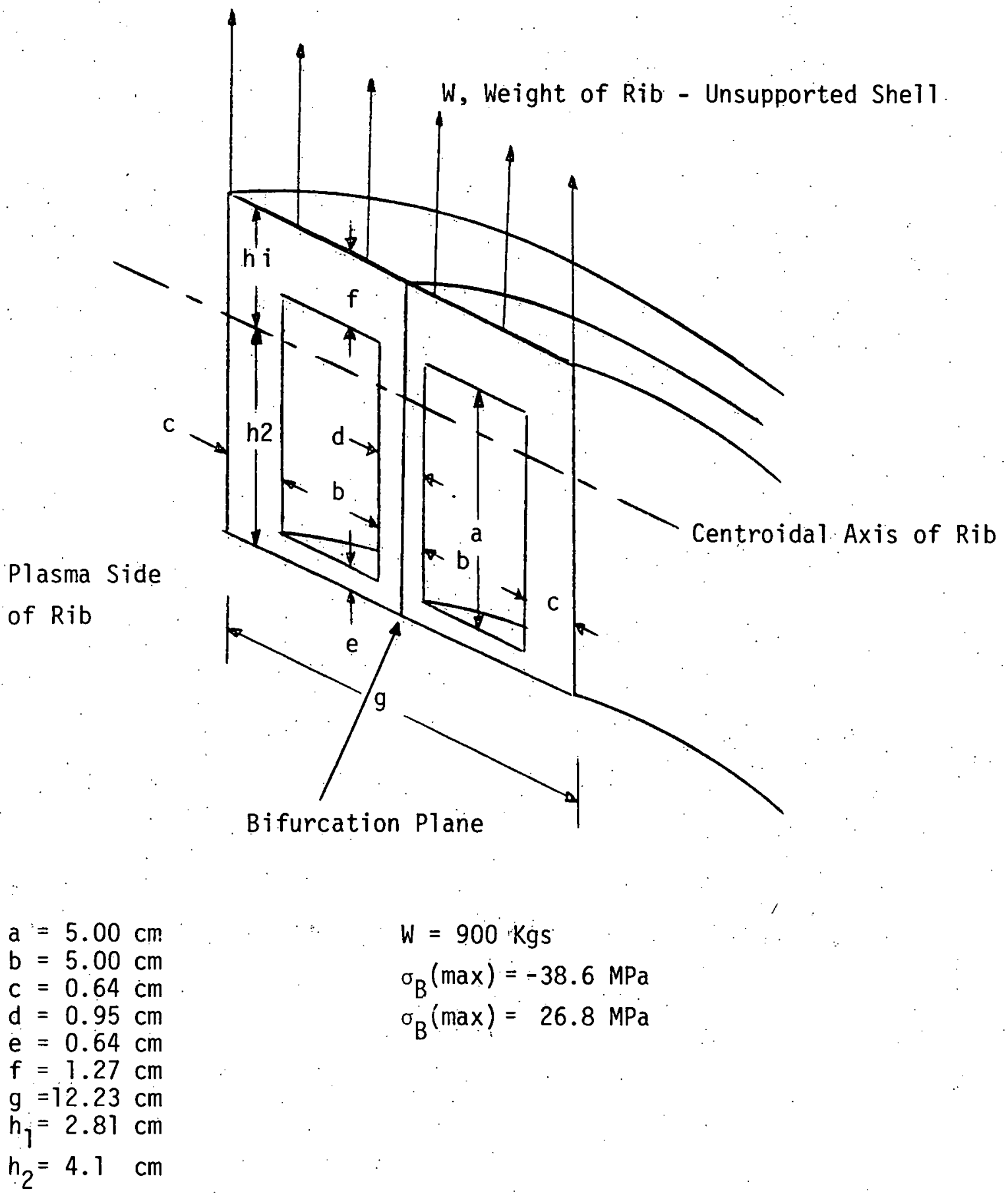

Figure 3-3. Potential Stiffener-Coolant Manifold Rib Design 
From this method of analysis, it appears that the mechanical bending stresses are relatively small and well below the maximum allowable stress. To determine the thermal bending stresses in the stiffening rib, one would have to model the the rib numerically. Since at this time the stiffening rib design is not optimized, the thermal stresses were not determined. The magnitude of these stresses would be significant and would have to be determined in future analysis.

It is recognized that supporting the rib from the top is not the most optimum location. Moving the support away from the top would decrease the bending moment acting in the rib. To minimize the bending produced by supporting the shell, the supports should be arranged to produce support that is tangent to the shell's surface. The location of these supports would depend on the number of support locations per rib. Also, the support system should be designed in such a way that it allows thermal expansion without constraint since it is desirable to minimize additional loads imposed on the vessel. 


\subsection{CONCEPTUAL DESIGN OF THE TWO COMPONENT VACUUM VESSEL SHELL}

Based upon the findings in the previous section, a conventional rib-stiffened shell was the structural element identified as being the most viable structural element for the DTHR reactor plasma vessel.

The reference vacuum vessel design is a two component structure. The structura] member consisting of the rib-stiffened shell that withstands the external static load of one atmosphere. The first wall is a tubular wall which shields the outer structural wall from the high surface heat flux.

The thin shell subjected to external pressure was initially sized from buckling rather than the stress considerations. The vacuum vessel is constructed from 316 SS. The fabricated vessel is made up of 10 identical modules to form the torus shown in Figure 4-1. This gives the vessel an added advantage in maintenance, allowing modular exchange of damaged vessel sections. The stiffeners and shell wall are designed for minimum mass. Because of the smaller inner equator of the toroidal envelope, the stiffening rib will have a varying area moment of inertia about the centroidal axis parallel to the shell, as it traverses the poloidal periphery of the toroidal shell. In addition, the shell wall will have a uniformly varying thickness as it traverses the poloidal periphery.

The stiffeners are designed to support their own weight, the shell's panel weight, and the weight from the tubular first wall. Each rib is supported by a three point suspension system. The stiffeners also serve as coolant manifolds for the tubular first wall.

Pressurized water has been determined to be an effective medium for removing the large thermal load imposed upon the vessel structure. The cooling is accomplished by circulating pressurized water in the bank of tubes which line the plasma side of the vacuum vessel. These tubes are aligned to run in the toroidal direction with coolant manifolds spaced approximately every four meters on the outer equator.

The following Table 4-1 lists the various parameters for conceptual design of the vacuum vessel. 
TABLE $4-1$

CONCEPTUAL DESIGN PARAMETERS OF THE DTHR VACUUM VESSEL

\section{Conceptual Design Description:}

Stainless steel two component vessel with rib reinforcing. The first wall consisting of a thermal tubular wall and the outer wall providing the shell's structural integrity. Ten identical assembilies make up the toroidal vessel located inside the TF coils.

Vacuum Veșsel and Tubular Wall Material

316 SS

Vessel Wall Thickness, Outer Toroidal Equator (max), cm

Vessel Wall Thickness, Inner Toroidal Equator $(\mathrm{min}), \mathrm{cm}$

Stiffener Area Moment of Inertia, Outer Toroidal Equator (max), $\mathrm{cm}^{4}$

Stiffener Area Moment of Inertia, Inner Toroidal Equator (min), $\mathrm{cm}^{4}$

Stiffener Rib Spacing, Outer Equator (max), m

Stiffener Rib Spacing, Inner Equator (min), cm

56.0

Coolant Tube Length, Toroidal Direction, $m$

4.0

Outret Pressure, $\mathrm{MPa}$

6.85

Channel $\triangle \mathrm{P}, \mathrm{MPa}$

0.04

Inlet Temperature, ${ }^{\circ} \mathrm{C}$

Outlet Temperature, ${ }^{\circ} \mathrm{C}$

Total Flow Rate, $\mathrm{kg} / \mathrm{sec}$

$39.8 \times 10^{5}$

Maximum Tube Temperature, ${ }^{\circ} \mathrm{C}$

Maximum She 11 Temperature, ${ }^{\circ} \mathrm{C}$

Pumping Power, kW

Film Coefficient, $\mathrm{W} / \mathrm{cm}^{2}-{ }^{\circ} \mathrm{C}$

Coolant Tube $00, \mathrm{~cm}$

Coolant Tube Wall Thickness, cm

Cycle, sec

Fult Power Burn Pulse, sec 


\subsection{THERMAL AND HYDRAULIC DESIGN}

The thermal and hydraulic design associated with the vacuum vessel are recognized as being one of the primary problem areas of the vacuum vessel system. The mechanical/structural design is solely constrained by the performance of the thermal/ hydraulic system. The following scoping analyses were carried out to identify the limiting thermal and hydraulic constraints of the reference design.

The source of the surface heating is from the alpha particles and the ionization of the neutral beam energy in the plasma. This surface flux will penetrate the first wall no more than $0.05 \mathrm{~mm}$. The magnitude and distribution is not fully determined and is dependent on a number of variables. A number of the thermal and hydraulic analyses of the vacuum vessel were based upon a very conservative estimate of this surface heat flux of $2.665 \mathrm{~mW} / \mathrm{m}^{2}$. This heat flux value is extremely conservative since the neutron wall loading of the DTHR is no higher than $2 \mathrm{MW} / \mathrm{m}^{2}$. A more realistic value would be $1 \mathrm{MW} / \mathrm{m}^{2}$. In addition to the surface heat flux heating, there is neutron and gamma heating acting throughout the entire vessel structure. The magnitude of this volumetric heating is rather constant for the first few centimeters of mass after which it decays exponentially. A value of $45 \mathrm{~W} / \mathrm{cm}^{3}$ has been previously identified as being a reasonable estimate of this neutron and gamma heating.

There has been no requirement set aside for this available thermal energy from the heated pressurized water coolant to be used in a power producing thermal cycle. The reference design is based on this assumption.

The strategy for cooling the vacuum vessel structure is to design a system which provides steady-state heat removal for the peak thermal load imposed upon the structure. The surface heat flux is collected on the tubular wall. The wall is designed solely for the purpose of removing the high surface flux and no additional function, such as structural support, is required of it.

Potential cooling schemes for the DTHR vacuum vessel were investigated by A. Y. Lee. Both helium gas and pressurized water coolants were considered for the cooling system analysis. 


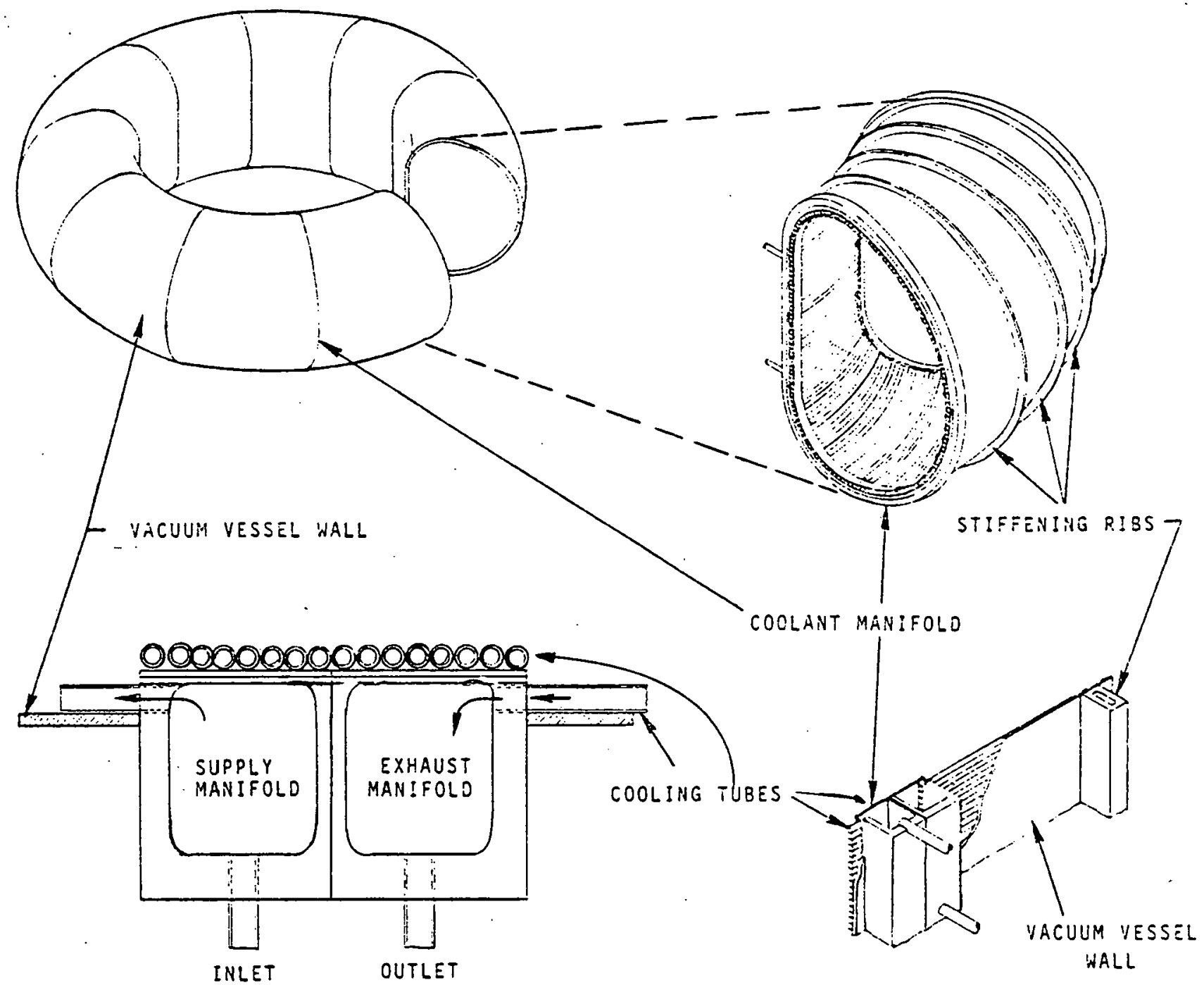

Figure 4-1. DTHR Vacuum Vessel Concept 
For water, two different potential pressures were investigated for the cooling system. The parameters and results are summarized in Table 4-2.

It can be seen from the table that operating the cooling system at a higher pressure water and subsequent higher permissible $\Delta T$ requires less coolant flow, thus requiring less pumping power. In addition, the maximum material temperature is closer to the selected allowable limit with a water coolant pressure of $6.89 \mathrm{MPa}$. However, higher pressures imply more structural material with additional neutron loss.

Because of its low density, use of gaseous helium as a coolant requires considerably higher pumping power. For effective helium cooling, the channel length should be kept short and the gas pressure high. Also, for efficient helium cooling, the tube should be a larger diameter. Even with these consilderations, the pumping power requirement for helium would be considerably higher than that for pressurized water.

From thermal design considerations, the water cooled thermal wall appears to be acceptable. However, the trade-off between pumping power of helium with the neutronics and activation effects of water would have to be evaluated. Also, the processing and control requirements for the conlant circulation system will also require evaluation from fabrication/assembly considerations. The manifolds may have to be spaced closer than the four meters assumed.

\subsection{STRESS ANALYSIS OF THE TUBULAR WALL}

The tubular wall has the unique characteristic that only half of its circumference is irradiated, and since it is round, the heat flux input reduces by a cosine function away from the normal point. Therefore, two-dimensional conduction in the radial and azimuthal directions yields a non-uniform temperature distribution on the inner wall. Also, the tubular first wall has increased surface area by a factor of $\pi$ versus the surface area for a flat first wall.

A simple one-dimensional steady-state temperature distribution was inadequate for determining the thermal stresses in the tubular wall. Thus, the two- 
TABLE $4-2$

SUMMARY OF DTHR VESSEL FIRST WALL COOLING PARAMETERS

Inlet Pressure, $\mathrm{MPa}$

Channel Length, m

Outlet Pressure, MPa

Channel $\triangle \mathrm{P}, \mathrm{MPa}$

Inlet Temperature, ${ }^{\circ} \mathrm{C}$

Outlet Temperature, ${ }^{\circ} \mathrm{C}$

Saturation Temperature at Channel Exit, ${ }^{\circ} \mathrm{C}$.

Total Flow Rate ${ }^{(1)}, \mathrm{kg} / \mathrm{hr}$

Maximum Tube Temperature, ${ }^{\circ} \mathrm{C}$

Maximum Shell Temperature, ${ }^{\circ} \mathrm{C}$

Pumping Power (2), kW
6.89

3.45

4

6.85

3.38

0.04

0.08

74

74

283

232

284

240

$39.8 \times 1.0^{5}$

$58.9 \times 10^{5}$

427

344

394

343

126

234 (1) Based on $360 \mathrm{~m}^{2}$ vessel surface area and a total of 9000 cooling
channels.

(2) Based on $50 \%$ pump efficiency. 
dimensional conduction problem was effectively modeled by finite elements to determine the temperature distribution in the tubular wa11. The two-dimensional model is illustrated in Figure 4-2. The problem was modeled as a transient case for which the thermal stresses which arise from the non-uniform temperature gradient were determined for the most significant operating point which was at the end of the full power pulse. (Because of computer cost and limited time for modeling purposes, the thermal results from the transient conditions for TNS -4 ( 1$)$ were used. Also, the inner equator wall thickness was used in the computer models.)

The thermal stresses associated with the tubular wall can be classified as general thermal stresses for the purpose of establishing allowable thermal stress limits in the wall. The ASME boiler and pressure vessel code, (29) Section NB-3213.13, classifies this type of thermally induced stress as "secondary". Because the thermal stresses contribute to local yielding, but will not reduce the limit load of the structure, these stresses may exceed the yield stress of the material with the limiting constraint being the cyclic fatigue damage to the structure. For design conditions, the allowable value of the maximum range of the stress intensity is $3 \mathrm{Sm}$, where $\mathrm{Sm}$ is the design stress intensity value. For the case investigated, the maximum tube temperature was $427^{\circ} \mathrm{C}$. This maximum temperature corresponds to a design stress intensity, Sm, for $316 \mathrm{SS}$ of $110.24 \mathrm{MPa}$. For the tube shown in Fiqure 4-3, there are a number of stresses that must be determined.

The stresses induced in the rigidly supported tube from the pressure of the coolant's weight are as follows:

$$
\begin{aligned}
& S_{\theta}=\frac{\rho r^{2}}{t}(1-\cos \theta) \\
& S_{x \theta}=\frac{\rho r}{t}(L / 2-X) \sin \theta \\
& S_{x}=-\frac{\rho X}{2 t}(L-X) \cos \theta+\frac{\rho r^{2}}{v t}(1-\cos \theta)
\end{aligned}
$$

Where $\rho$ is weight/unit volume of coolant. 


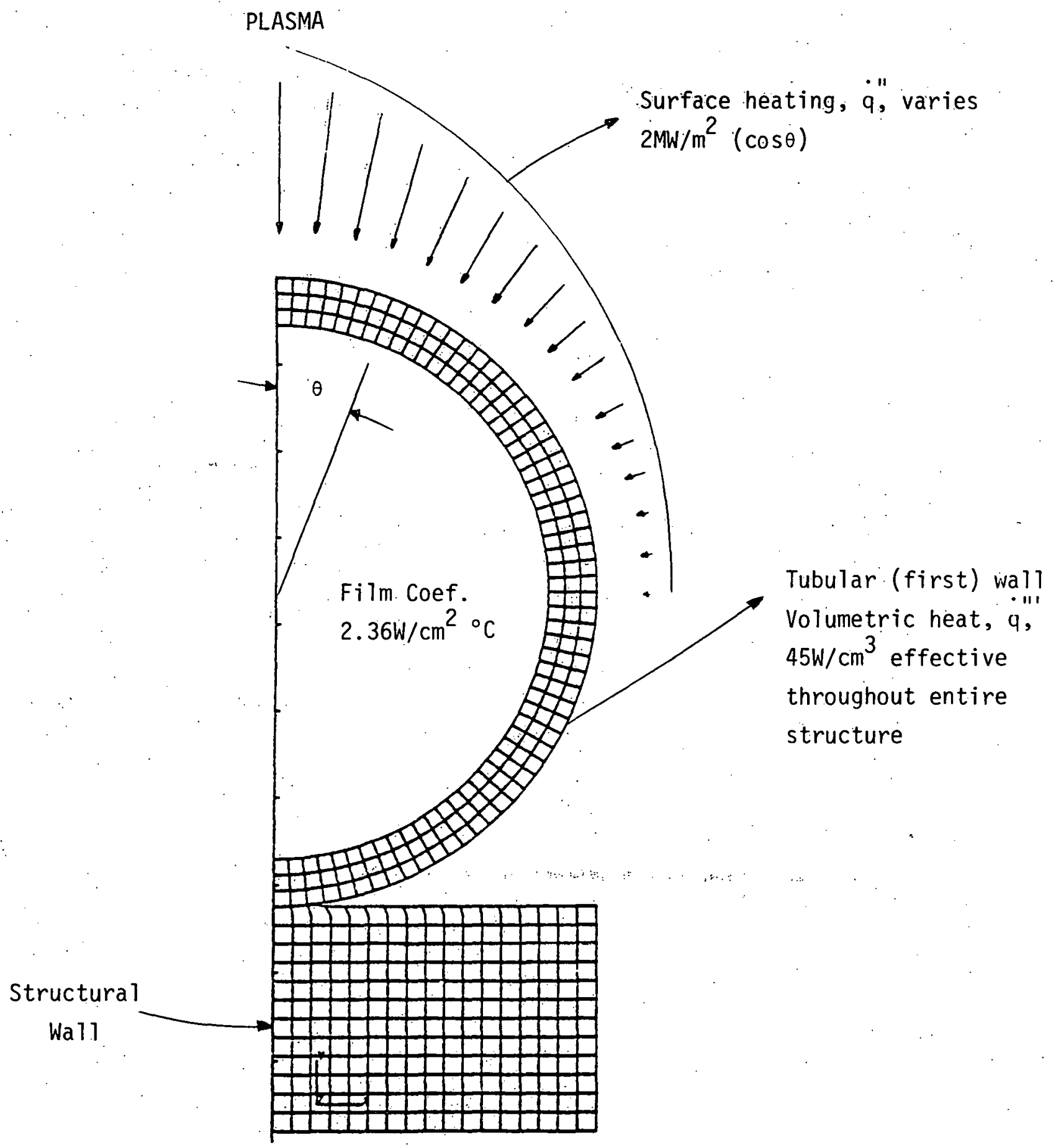

Figure 4-2. Two-Dimensional Finite Element Model at the Thermal-Structural Wall Cross-Section 
The hoop stress, $S_{\theta}$, and the shear stress, $S_{x \theta}$, induced from the pressure of the coolant's weight are negligible and are not worth considering. The longitudinal stress induced from rigidly supporting the coolant tube, an interval (L), is also negligible since the tube is supported over the entire span.

The membrane stress continuously induced from the coolant pressure acting on ! the shell wall is:

$$
v \theta_{m}=\frac{P R}{t}
$$

The calculated value is $42.75 \mathrm{MPa}$. The longitudinal stress induced from the coolant's internal pressure is one half the calculated hoop stress. This value being $21.38 \mathrm{MPa}$.

The maximum thermal stress is acting at the point where the surface flux is normal to tube surface. This value being $215.8 \mathrm{MPa}$ for the inside of the tube and $-184.7 \mathrm{MPa}$ for the outside of the tube. The finite element model has the appropriate boundary conditions so that the thermal stress calculated represents the local and diametral stresses.

The sum of the primary and secondary stresses at a point gives the stress amplitude, $S_{a}$, for that point. This stress intensity amplitude is found for the most severe stressed region and is used to determine the number of cycles the structure is suitable for under cyclic application of loads and thermal conditions.

The stress amplitude is maximum at the point where the surface flux is normal to the wall. The value of the stress amplitude at this point is $258.5 \mathrm{MPa}$. This value is less than the allowable maximum limit of $3 \mathrm{Sm}$, permitting direct use of the design fatigue curve in Figure 4-4. If the $3 \mathrm{Sm}$ limit on the range of primary plus secondary stress intensity were exceeded, other requirements must be met for one to evaluate the fatigue behavior of the structure. These requirements are outlined in Section NB-3228.3 of the ASME Boiler and Pressure Vessel Code.(29)

Examination of the design fatigue curve in Figure 4-4 shows that a stress amplitude of $258.5 \mathrm{MPa}$ corresponds to a cyclic life of $2 \times 10^{5}$ cycles. $2 \times 10^{5}$ cycles for DTHR applications is approximately two years of use. The number of 


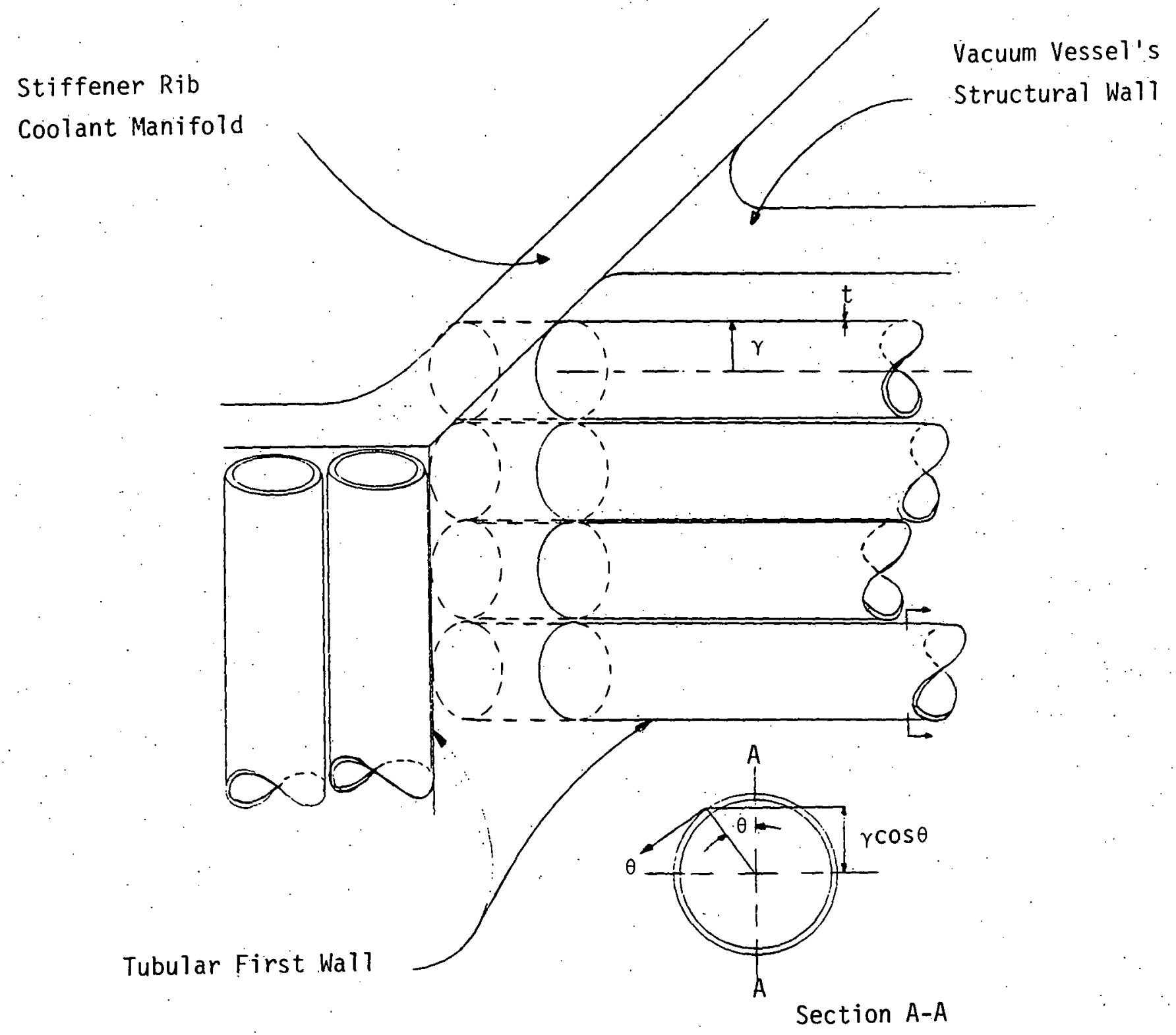

Figure 4-3. Tubular (First) Wall 


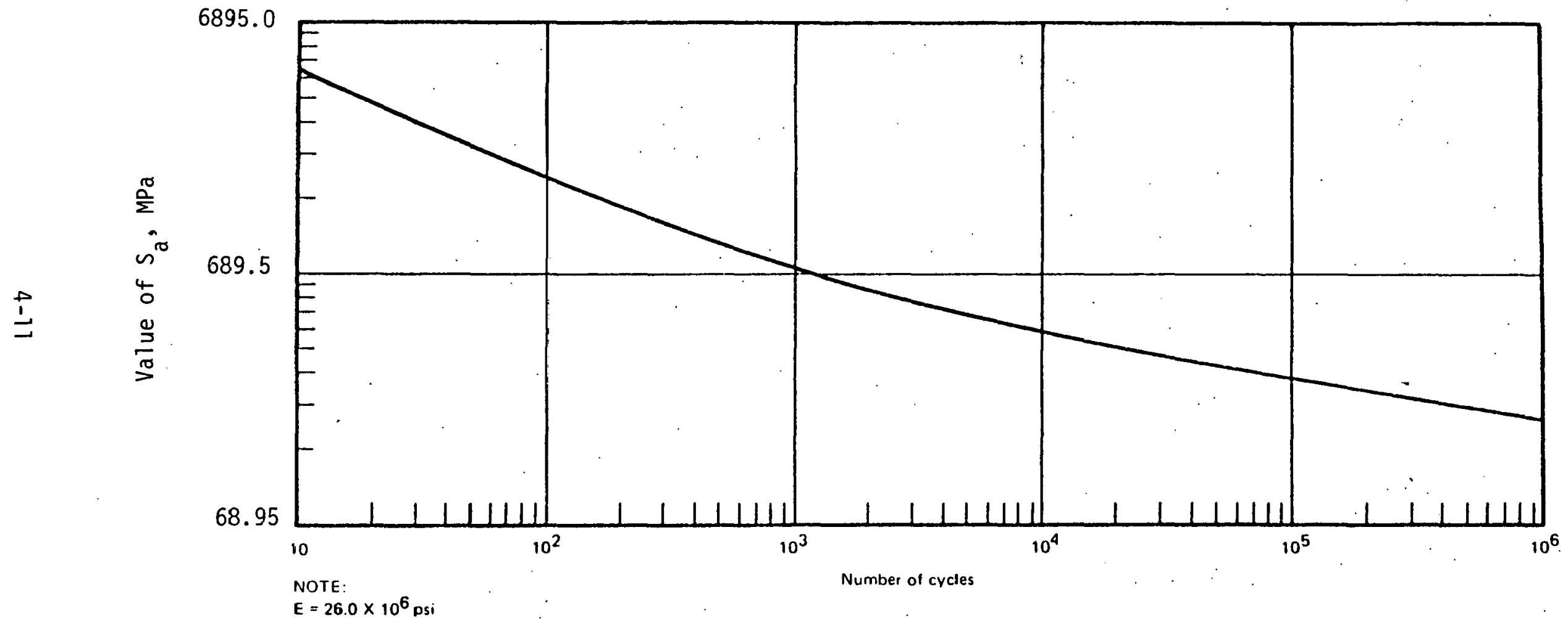

Figure 4-4. Design Fatigue Curve for Austenitic Steels, Nickel-Chromium-Iron Alloy, Nickel-Iron-Chromium Alloy, and Nickel-Copper Alloy 
cycles could be increased by a factor of 5 if the maximum stress amplitude is reduced by approximately $30 \%$. This goal of relieving the stress amplitude by $30 \%$ is highly probable. The conditions for which the tubular wall could achieve this performance would have to be identified by a parametric study involving the various controlling parameters. These variables consist of the magnitude of the surface flux, and volumetric heating and the coolant pressure.

The study used a very conservative estimation for the surface flux. B. using a more representative surface flux value, the design requirement of $10^{6}$ cycles could possibly, be attained.

The separately cooled inner tubular wall eliminates all the surface heat flux from the structural wall of the vacuum vessel, thus the only heat infut to the structural walls is the neutron-gamma irradiation which is $45 \mathrm{~W} / \mathrm{cm}^{3}$. The removal of this thermal energy in the structural wall is achieved by conduction to the tubular wall where it is removed by forced convection. This conduction problem was effectively handled by the finite element model previously described for the tube analysis. The loading history for this model was for TNS burn cycle, where the turn pulse was for 30 seconds.

The results $i l l u s t r a t e d$ that the tube quickly reached steady-state temperatures while the back wall had considerable thermal lag. The maximum temperature of the back wall was not reached until the end of the burn pulse. At the end of the 30 second burn pulse, the tube quickly recovered to its equilibrium temperature while the wall needed approximately 15 seconds to recover its equilibrium temperature. Since the transient thermal/hydraulic analyses were for the TNS cycle, one can only make a conjecture as to the thermal behavior of the vessel wall for the longer DTHR cycle. The longer cycle would not directly affect the thermal performance of the tube. Steady-state conditions were reached during the 30 second TNS burn cycle. However, it was not evident from the analysis that the structural panel reached steady-state temperatures during this cycle: Thus, for a 
longer burn pulse, it is probable that there would be an increase in the temperature gradient, directly affecting the magnitude of the thermal stresses in the structural wall. To accurately assess the performance of the referenced twocomponent vacuum vessel wall, it is necessary to numerically model the structure using the DTHR burn cycle. This would establish the time when the temperatures in the structure reach steady-state and also make evident the maximum thermal gradient in the structural wall.

The finite element results indicated that the maximum thermal stress intensity in the structural panel was $24.1 \mathrm{MPa}$. This stress was located in the inner side of the wall near the contact point of the tube. Since the magnitude of the mechanical stress in the panel section, which is induced from the external pressure acting on the shell, is indeterminate from hand calculations, one is unable to find the stress amplitude that the stress amplitude for the panel section would fall below the 182.7 MPa level which is the stress amplitude limit for meeting the design fatigue requirements of the vessel having a lifetime of $10^{6}$ cycles.

A number of options are available to increase the cooling efficiency of the structural wall if the present reference design proves to be inadequate for DTHR applications. One such scheme would be to flatten out the tube contact point with the structural wall. This would increase the conduction area between the two bodies allowing the heat conduction from the structural wall to the tube to increase which reduces the thermal lag that is evident with the present design. One could also increase the film coefficient to the coolant which would remove the heat at a faster rate. However, this would increase the pumping power needed which should be avoided, if possible.

Since the ribs are shielded from the surface heat flux, the only thermal energy is the internally generated heat, due to neutron and gamma irradiation. The magnitude of this thermal energy is dependent upon the mass of the stiffener rib, which in turn will determine the amount of cooling needed to accommodate the internally generated heat. 


\subsection{STIFFENER - COOLANT MANIFOLD RIB DESIGN CONCEPT}

Further reference design of the stiffener-coolant manifold and stiffening rib is dependent upon further development work on the overall reactor layout and the mechanical characteristics of the cooling system decided upon for the tubular first wall. The reactor layout is of importance because the rib is sized from stability analysis to have a specified area moment of inertia about its centroidal axis parallel to the shell surface. Although this area moment of inertia varies as the rib transverses toward the inner equator, it must have a maximum moment of inertia of $250 \mathrm{~cm}^{4}$ at the outer toroidal equator. The area moment of inertia of the ribs about the centroidal axis parallel to the shell is very dependent upon the depth of the rib perpendicular to the centroidal axis. This radial rib depth is limited by the allocated space for the vacuum vessel inside the DTHR or TNS reactor. Also, the coolant internal pressure acting on the surface of the stiffener-coolant manifold must be considered in the final design. The internal coolant pressure is dependent upon the coolant and geometric characteristics of the tubular wall chosen to effectively cool the vacuum vessel. After these parameters are determined, the ribs can be efficiently sized in regard to mass and radial cross-sectional dimensions which minimizes thermal and mechanical stresses. Thus, a structural, thermal and hydraulic trade-off is required to determine these controlling parameters.

The current reference design for the stiffener-coolant manifold rib is illustrated in Figure 4-5. The schematic highlights the design concepts, but the actual dimensions of the rib cannot be determined at this time. The meridian midplane of the rib is the bifurcation plane of the modules. The technique for attaching the modules together should be such that the rib can accommodate toroidal expansion but still demonstrate rigid coupling for in-plane bending.

The intermittent stiffening ribs, which provide only external support to the shell, is illustrated in Figure 4-6. The ribs must have internal coolant channels to accommodate neutron and gamma heating. The channel location and dimensions need to be determined so that the final design yields optimum thermal and mechanical stress. 


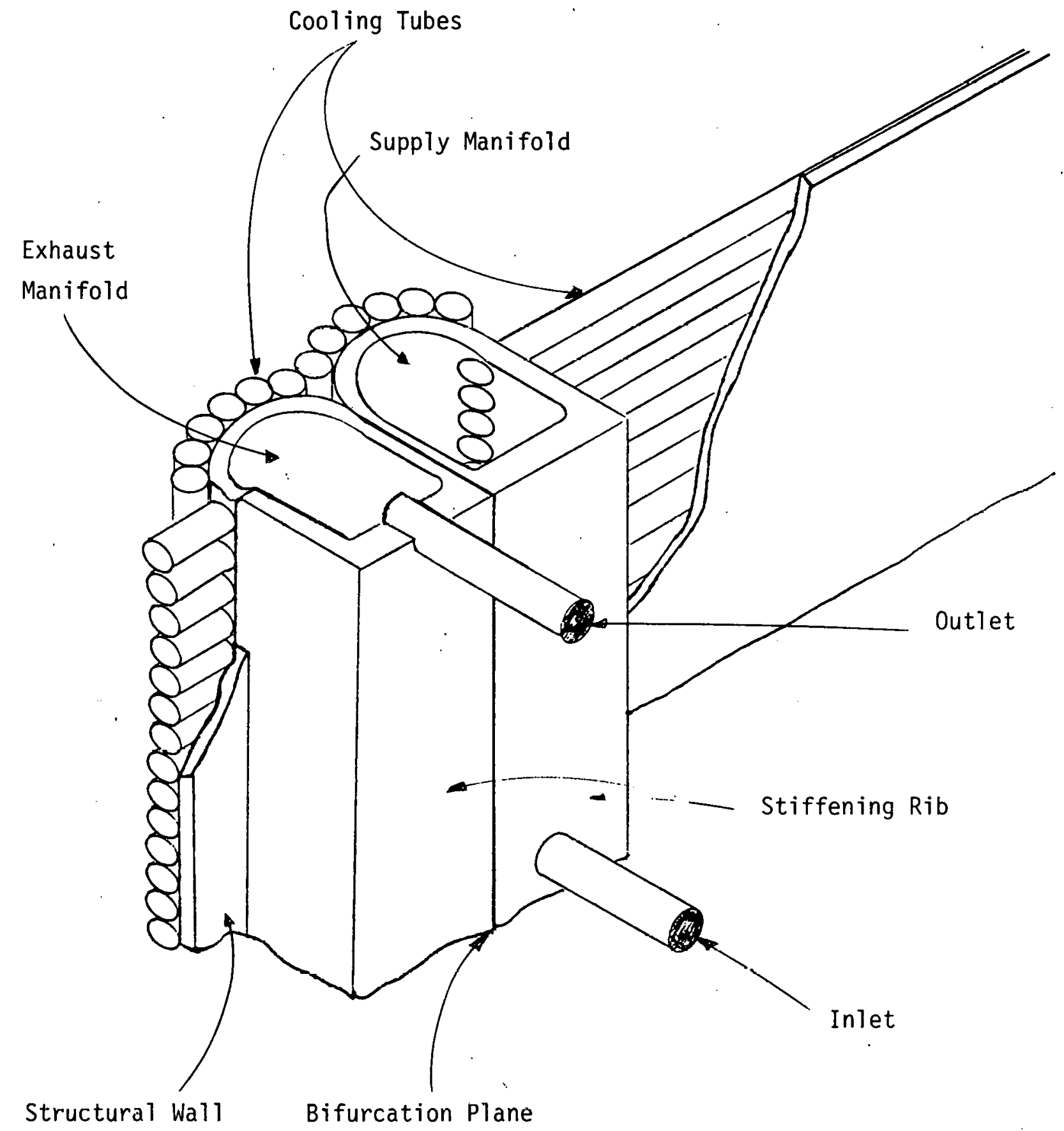

Figure 4-5. Stiffener-Coolant Manifold Rib Concept 


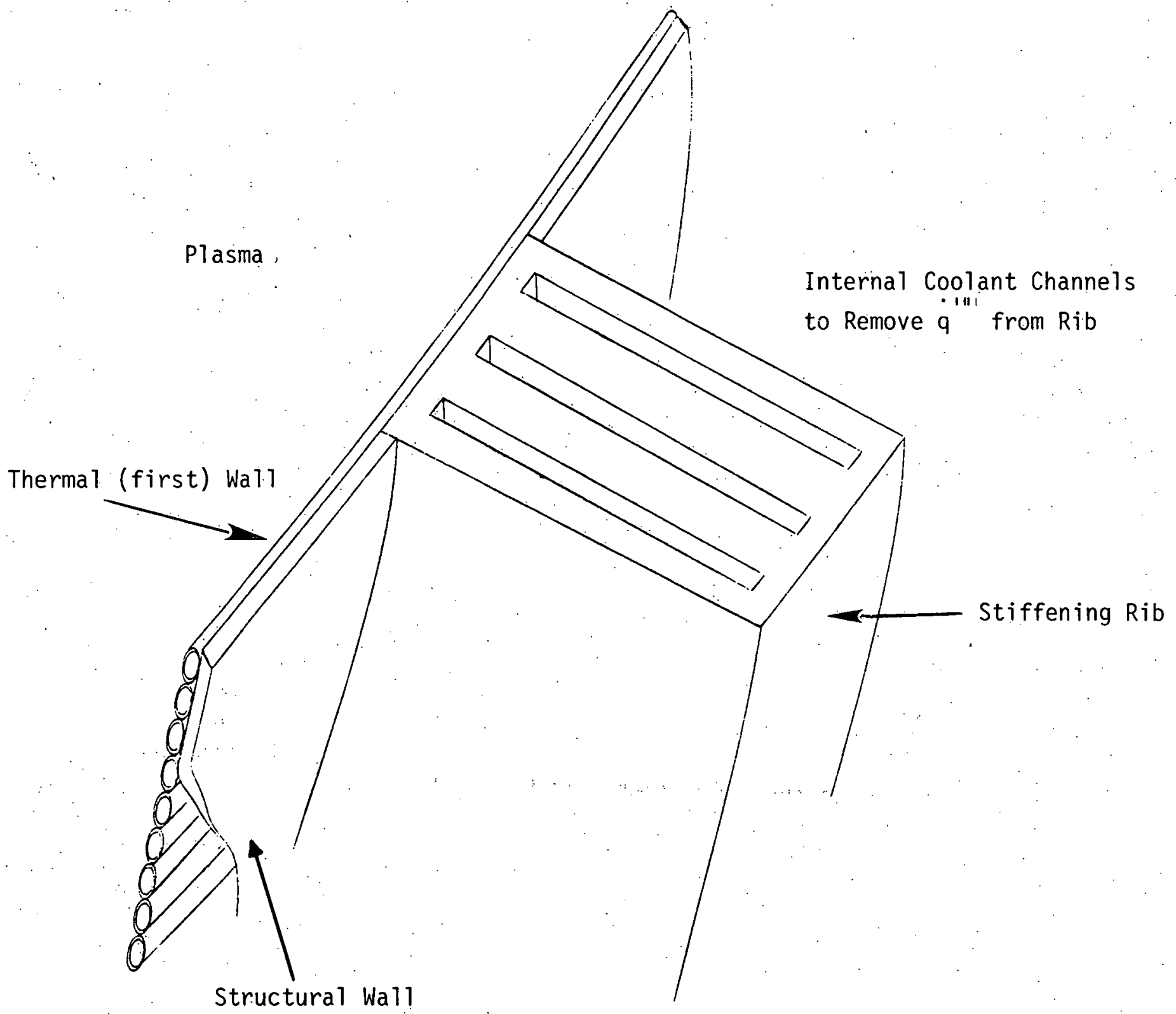

Figure 4-6. Stiffener Rib Concept 


\subsection{SUMMARY OF THE TWO-COMPONENT VACUUM VESSEL DESIGN AND CONCLUSIONS}

- The two-component rib-stiffened vacuum vessel appears to be a viable concept for TNS and DTHR reactor application.

- The stress and buckling analysis shows that the rib-stiffened shell has structural integrity according to the criteria established in this report. Further detailed stability analysis for the D meridian torus should be performed by utilizing one of the numerical thin shell stability codes.

- The stress analysis of the tubular wall indicates that the stress amplitude, the sum of the thermal and mechanical stresses, has a cyclic life of $2 \times 10^{5}$ cycles. This represents a DTHR usage period of approximately two years.

- The design concept of the stiffening rib and stiffener-manifold rib is highlighted. Further detailed design is contingent upon the geometric characteristics of the overall reactor layout and also the mechanical characteristics of the coolant system.

- Under pulsed operation, the temperature in the tubular first wall reached steady-state relatively quickly, while the temperature response of the outer structural wall had thermal lag.

- Structural, neutronic, thermal and hydraulic trade-off study is necessary to determine the optimum coolant parameters.

- The dynamic load on the vacuum vessel caused from plasma disruptions which induce large electric current flow in the vessel needs to be determined.

- It is recognized that the reference design will undoubtedly contain manufacturing and fabrication complexities.

- A low Z material coating of the tube outer surface may be required to reduce the impurities released to the plasma from the stainless steel tube surface.

In performing various analyses for the vacuum vessel study, it was often necessary to use extrapolations and approximate techniques to effect a particular solution. More sophisticated numerical modeling and parametric studies were not possible because of the limited time to complete the investigation. Based on the current findings in this paper, it is felt that the reference design of the two-component vacuum vessel has demonstrated to be a viable concept and further, more in-depth analyses are warranted. 


\subsection{REFERENCES}

(1) TNS Quarterly Progress Report, July-Sept. 1976, IIFPS-TPIE-049, October 1976.

(2) McCormick, C. W., "The Nastran User's Manual," (level 15), NASA, (1972).

(3) Bushne11, D., "BOSOR 5 - Program for Buckling of Elastic-Plastic Complex Shells of Revolution Including Large Deformation and Creep," Lockheed Research Laboratory, Palo Alto, California, (1976).

(4) Kalnins, A., "Static, Free Vibration, and Stability Analysis of Thin, Elastic Sheils of Revolution," AffDL-TR-68-144, Air Force Systems Command, Wright-Patterson Air Force Base, Ohio, (1969).

(5) Sobel, L. H., and Flugge, W., "Stability of Toroidal Shells under Uniform External Pressure," AIAA Journa1, Vol.5, No.3, pp. 425-431, (March 1967).

(6) Romano, F., and Kempner, J., "Stresses in Short Noncircular Cylindrical Shells Under Laternal Pressure," Journal of Applied Mechanics, Transactions of the ASME, Vol. 29, pp. 669-674, (1962).

(7) Maching, 0., "Uber Stabilitatsprobleme von torusformigen Schalen," Wiss. Z. Hochsch. Verkehrswesen Dresden 4, 179-204, (1956).

(8) Jordan, P. F., "Vibration and Buckling of Pressurized Torus Shells," AIAA Paper 66-445, (1966).

(9) Stancampiano, "Preliminary Structural Stability Considerations of the TNS Vacuum Vessel," Internal Note, Westinghouse Fusion Power Systems.

(10) Brush, P. O., and Almroth, B. 0., "Buckling of Bars, Plates, and Shells," McGraw-Hill, Inc., New York, 1975.

(11) Kraus, H., "Thin Elastic Shel1s," Wiley, New York, 1967.

(12) Flugge, W., "Stresses in Shells," 2nd Ed., Springer, Berlin, 1973.

(13) Novozhelov, V. V., "The Theory of Thin Shells," P. Noordhoff Ltd., Groningen, The Netheriands, 1959.

(14) Weingarten, V. I., "Buckling of Thin Wall Circular Cylinders," NASA SP8007, (1968).

(15) Goldenvieyer, A. L., "Theory of Elastic Thin She11s," Pergamon Press, (1961). 


\section{REFERENCES (Continued)}

(16) Yao; J. C., and Jenkins, W. C., "Buckling of Elliptic Cylinders Under Normal Pressure," AIAA Journal, Vol. 8, No. 1, pp. 22-27, (1970)

(17) Wang, C. T., and Rao, G. V. R., "A Study of an Analagous Model Giving the Nonlinear Characteristics in the Buckling Theory of Sandwich Cyl inders," Journal of the Aeronautical Science, Vol. 19, 1952, pp. 93-100.

(18) Reissner, E., "Small Bending and Stretching of Sandwich-Type Shells," NACA Report No. 975, 1950 (formerly NACA TN 1832).

(19) Theocaris, P. S., and P. W. Hill, "Inelastic Buckling of Rib-Cored Sandwich Cylinders Under External Hydrostatic Pressure," Journal of Applied Mechanics, Transaction of the ASME, Vol. 33, pp. 593-600 (1966).

(20) Stein, M., and J. Mayers, "A Small Deflection Theory for Curved Sandwich Plates," NACA Report No. 1008, 1951.

(21) Fulton, R. E., "Buckling Analysis and Optimum Proportions of Sandwich Cylindrical Shells Under Hydrostatic Pressure," Structural Research Series No. 199, University of Illinois, Urbana, Illinois, (1960).

(22) Simitses, G. J., "A Note on the General Instability of Eccentrically Stiffened Cylinders," Journal of Aircraft, Vo1. 4, No. 5, pp. 473-475, SeptOct, 1967.

(23). Merk, H. R., "A Survey of Methods of Stability Analysis of Ring-Stiffened Cylinders Under Hydrostatic Pressure," Journal of Engineering for Industry, 1965.

(24) Saunders, H. E., and Windenburg, D. F., "Strength of Thin Cylindrical Shells Under External Pressure," Pressure Vessel and Piping Design, Collected Papers 1927-1959, ASME, New York.

(25) Bijlaard, P. P., "Buckling Under External Pressure of Cylindrical She1ls Evenly Stiffened by Rings Only," Journal of the Aeronautical Sciences, Vol. 24, No. 6, pp. 437-447, 1957.

(26) Clark, R. A., Gilroy, T. I. and Reissner, E., "Stresses and Deformations of Toroidal Shells of Elliptical Cross Section," J. Applied Mechanics, pp. 37-48, (March, 1952).

(27) Roark, R. J., and Young, W. C., Formulas for Stress and Strain, 5th Edition, McGraw-Hill, New York, New York, (1975).

(28) Flügge, W., Handbook of Engineering Mechanics, 1st Edition, McGraw-Hill, New York, New York, (1962).

(29) ASME Boiler and Pressure Vessel Code, 1977 Code Cases - Nuclear Components, 1977 Edition, Julv 1, 1977, Cases N-47 (1592-10), Approved on March 23, 1977. 